\title{
Recent Advances of Pharmaceutical Process Chemistry and Its Innovation in China: Part 1
}

\author{
Pei Tang ${ }^{1}$ Biao Nie ${ }^{2}$ Jiuzhong Huang ${ }^{2}$ Yingjun Zhang ${ }^{2,3}$ ji Zhang ${ }^{2,3}$ Fen-er Chen ${ }^{1,4}$
}

${ }^{1}$ Sichuan Research Center for Drug Precision Industrial Technology, West China School of Pharmacy, Sichuan University, Chengdu, China

2 HEC Pharm Group, HEC R\&D Center, Guangdong, People's Republic of China

${ }^{3}$ The State Key Laboratory of Anti-Infective Drug Development, Guangdong, People's Republic of China

${ }^{4}$ Engineering Center of Catalysis and Synthesis for Chiral Molecules, Department of Chemistry, Fudan University, Shanghai, People's Republic of China

Pharmaceut Fronts 2020;2:e28-e54.

\author{
Address for correspondence Fen-er Chen, PhD, Engineering Center of \\ Catalysis and Synthesis for Chiral Molecules, Department of \\ Chemistry, Fudan University, 220 Handan Road, Shanghai, 200433, \\ People's Republic of China (e-mail: rfchen@fudan.edu.cn).
}

Ji Zhang, PhD, The State Key Laboratory of Anti-Infective Drug Development, Guangdong, 523871, People's Republic of China (e-mail: zhangji@hecpharm.com).

\author{
Abstract \\ Keywords \\ - pharmaceutical \\ industry \\ - green process \\ - asymmetric catalysis \\ - chiral drugs \\ - stereoselectivity
}

This review article summarizes recent developments and innovations in China's pharmaceutical process chemistry over the last several decades. Case studies of dozens of blockbuster drug processes are presented, including bulk drugs, such as the overthe-counter medicine biotin, demonstrating China's substantial effort to green its pharmaceutical processes. Owing to the increasing stringent environmental regulations, Chinese chemists have invented several cutting-edge and eco-friendly synthetic methods that are beneficial to environmental protection. Applied to large-scale industrial production, these processes have a greatly reduced environmental footprint, promoting the sustainable development of global economy and health.

\section{Introduction}

With the rapid improvement in China's modern industry and the Chinese people's standard of living over the past decades, China has become a major player in pharmaceutical production. China is also a country experiencing a rapid increase in its aging population, which has coincided with the massive consumption of medicine. The needs of basic chemical and pharmaceutical industries have solid foundations. According to recent statistics, ${ }^{1}$ in 2017 , there were more than 2,000 pharmaceutical companies in China producing active pharmaceutical ingredients (APIs). These companies are collectively producing 1,600 various kinds of APIs with a total production capacity of 3.478 million tons, of which exports exceeded 1 million tons at a value of nearly 210 billion RMB (Chinese yuan). Both drug production capacity and export scale ranked No. 1 in the world. In the meantime, the size of the Chinese API market reached 573.5 billion RMB in 2017, and the market of pharmaceutical intermediates achieved 430 billion RMB.
-Fig. 1 shows the sales revenue of China's APIs from 2010 to 2017. Therefore, it is very important to develop a sustainable Chinese pharmaceutical industry that is beneficial not only to the Chinese people, but also to the world.

Several major reasons have prompted the Chinese pharmaceutical industry and academic laboratories to explore, innovate, and develop novel green technologies in pharmaceutical processes. First, the Chinese government has introduced stricter environmental protection regulations in recent years, incentivizing pharmaceutical companies to upgrade their technology and to employ green synthetic methods and processes. Second, the governmentled procurement policy has moderated drug prices to a reasonably low point, which has been a driving force for reducing drug production costs. Third, Chinese pharmaceutical companies want to survive in a competitive market, requiring the development of much greener and safer operations. Finally, a series of safety-related accidents have also educated the Chinese society and urged the need for state-of- received

August 20, 2019

accepted

September 25, 2019
DOI https://doi.org/

$10.1055 / \mathrm{s}-0040-1701652$. ISSN 2628-5088. (c) 2020 Georg Thieme Verlag KG Stuttgart - New York
License terms

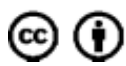




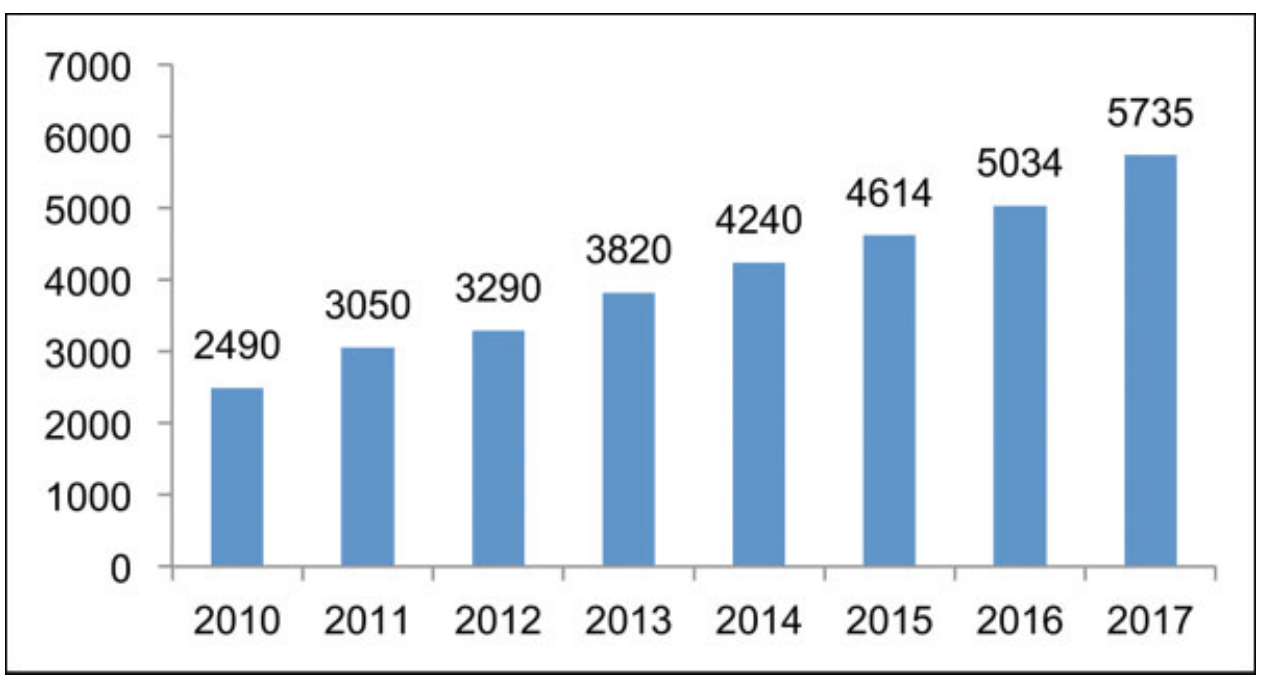

Fig. 1 Chinese API sale revenue (RMB, unit: billion yuan) from 2010 to 2017.

the-art and safe processes. At the same time, China wants its APIs to be competitive in the international market by lowering production costs and improving quality, while also minimizing the impact on the environment to preserve China's abundant natural resources.

Therefore, by applying the guiding principles of green chemistry, ${ }^{2}$ and learning from the successes of multinational pharmaceutical companies in the United States. and Europe, ${ }^{3-5}$ Chinese academics and pharmaceutical chemists have initiated the exploration and innovation of green pharmaceutical processes since the turn of the 21stcentury. Chinese chemists have also vigorously developed their own revolutionary synthetic processes and have achieved some outstanding innovative processes for drug production based on the economic rationality and continuous availability of the starting materials. Herein, we review the recent progress of the pharmaceutical processes in China overthe past decades, but some selected examples may not be comprehensive and lacking in details due to the protection of their intellectual properties.

\section{Specific Examples and Related Innovation of Industrialized Application of Green Pharmaceuticals}

\section{Ongoing Pursuit of Practical Biotin Process}

Biotin 1 (-Fig. 2), a water-soluble B series vitamin, was first isolated from egg yolk in $1936 .{ }^{6}$ It distributes widely in microorganisms, plants, and animals, and plays crucial roles as a coenzyme in the metabolism of fatty acids, sugars, and $\alpha$ amino acids. ${ }^{7}$

The chemical synthesis of biotin was accomplishedwith the first total synthesis of racemic biotin and subsequent optical resolution by Harris et al fromMerck in $1943 .{ }^{8}$ Subsequently, Goldberg and Sternbach at Hoffmann-La Roche applied for patents on the first commercially applicable biotin synthesis in 1946. ${ }^{9}$ As shown in Scheme 1, the cyclic anhydride 3 was synthesized from commercially available fumaric acid (2), and could be converted into the racemic sulfonium salt $\mathbf{4}$ after

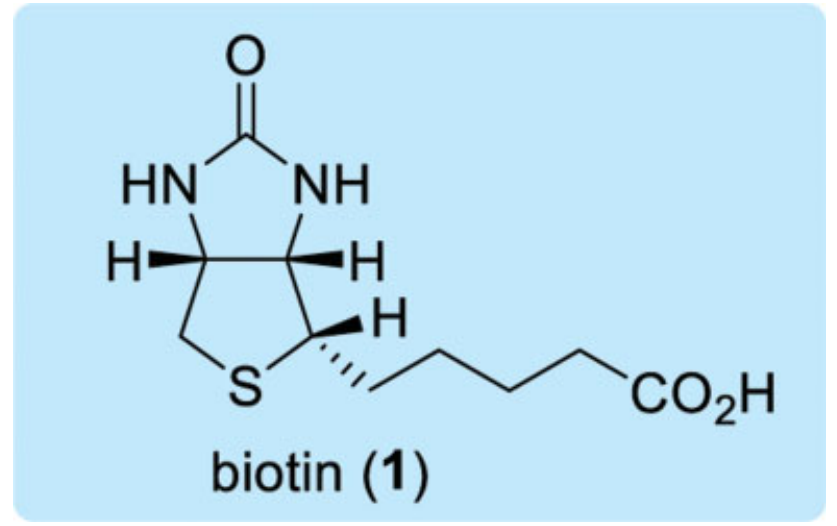

Fig. 2 Structure of biotin (1).

several functional group transformations. Subsequent optical resolution of 4 by the use of camphorsulfonic acid and two additional operations smoothly delivered biotin. Since these pioneering works, the synthesis of biotin has long challenged industrial and academic chemists, and continued to stimulate interest in developing an optimum synthetic approach toward this legendary molecule. ${ }^{7}$ In 1970, Gerecke and coworkers at Hoffmann-La Roche significantly improved the original Goldberg-Sternbach approach, ${ }^{10}$ which featured a ring opening of the cyclic anhydride $\mathbf{3}$ to a racemic mixture of hemiester $\mathbf{5}$ by alcoholysis, and the following resolution was realized via the crystalline ephedrine salt of the diastereomeric hemiester. Subsequent reduction/cyclization sequence delivered chiral lactone $\mathbf{6}$, which could then be built up in several steps into biotin viaa thiation/Grignard/homologation sequence. It is worth noting that this procedure was operated on a commercial scale by Roche until the 1990s, and lactone $\mathbf{6}$ has been the most commonly utilized chiral intermediate in the processes delivering biotin. $^{7}$

In 2001, Chen, one of the authors of this article, developed an improved resolution route for the synthesis of chiral Roche's lactone 6 at Fudan University (Scheme 2). ${ }^{11}$ Central 


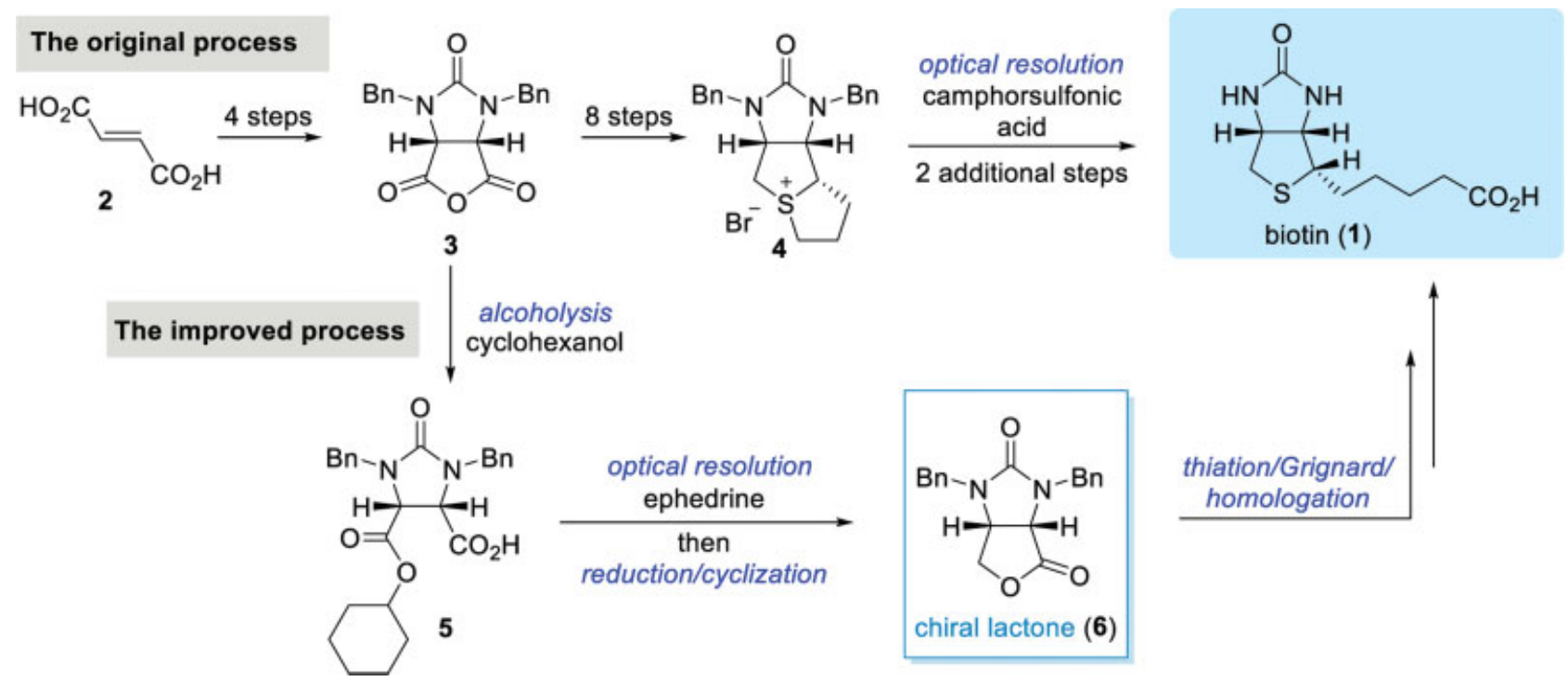

Scheme 1 The Roche's original and improved process.

in the synthesis was the replacementof the ephedrine with chloramphenicol base $\mathbf{8}$ as the resolving agent, providing the desired enantioenriched half-ester 9 in 37\% yield, which was comparable to the yield obtained via Roche's approach.

An impressive development of efficient asymmetric strategies-that is, the direct conversion of cyclic meso-anhydride 3 to optically active lactone $\mathbf{6}$-was realized by Matsuki et al in $1993 .{ }^{12}$ Employing $(R)$-BINAL-H (11), the asymmetric reduction of $\mathbf{3}$ delivered $\mathbf{6}$ in $76 \%$ yield and $90 \%$ ee. Subsequently, this transformation was further extended by Chen et al to a method utilizing thiocarboxylic anhydride 10, which was readily synthesized from anhydride $\mathbf{3}$ via thiation (Scheme 3). ${ }^{13}$ Reaction of $\mathbf{1 0}$ in the presence of $(R)$-BINAL-H (11) smoothly afforded thiolactone $\mathbf{1 2}$ in a higher efficiency with $83 \%$ yield and $98.5 \%$ ee. Enantioenriched 12 could then be built up in several steps into biotin. Moreover, the plausible mechanism of this enantioselective transformation was proposed by Chen, as illustrated in Scheme 3, and the
$S i$-face of the carbonyl group should be selectively reduced by means of a favorable $n-\pi^{*}$ interaction between the oxygen nonbonding orbital and the lowest unoccupied molecular orbital (LUMO) of the thioanhydride moiety.

In 1999, Shimizu et al reported the enantioselective reduction of meso- $\mathrm{N}$-benzyl imide $\mathbf{1 3}$ into the corresponding chiral hydroxylactam 14 with borane in the presence of an oxazaborolidine catalyst derived from $L$-threonine. Despite a $98 \% e e$, the yield of $\mathbf{1 4}$ was moderate (65\%). ${ }^{14}$ Indeed, this asymmetric CBS (Corey-Bakshi-Shibata)-type reduction has been studied extensively by Chen and coworkers (Scheme 4). ${ }^{15}$ With in situ generated borane from cheap, safe, and convenient lithium hydride/sodium hydride and boron trifluoride etherate, they prepared three types of oxazaborolidine catalysts, chloramphenicol base derivative $\mathbf{1 5}$, polymer-supported sulfonamide $\mathbf{1 6}$, and polymer-supported amino alcohol 17. Treatment of imide $\mathbf{1 3}$ with these chiral oxazaborolidines provided hydroxylactam $\mathbf{1 4}$ in<smiles>COC(=O)C1C(C(C)=O)N(Cc2ccccc2)C(=O)N1Cc1ccccc1</smiles>
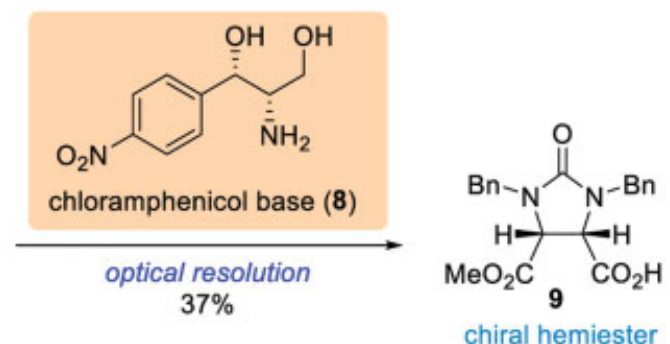
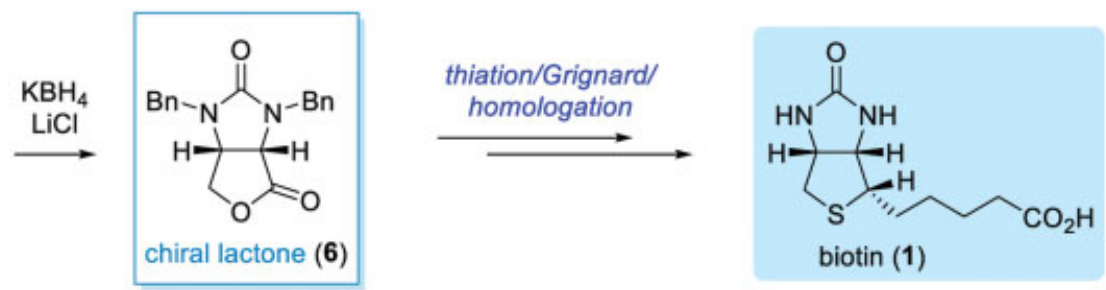

Scheme 2 The improved resolution approach by Chen. 

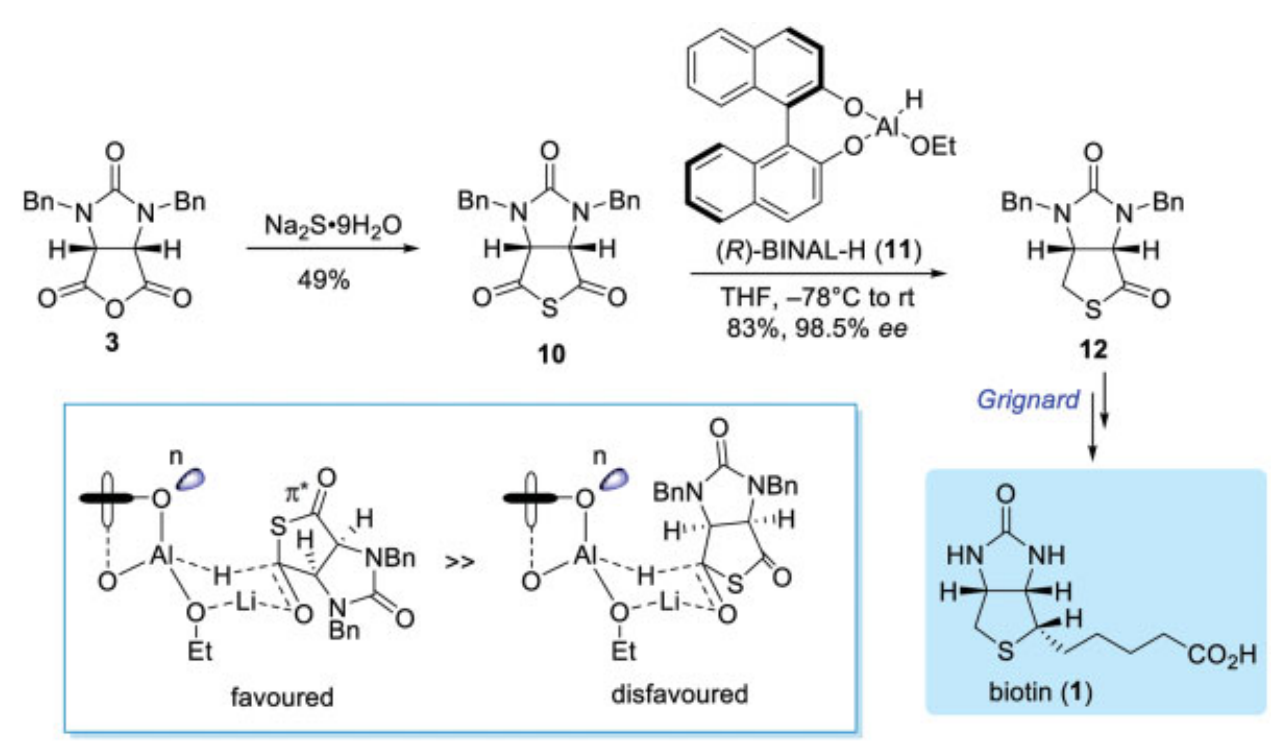

Scheme 3 Chen's asymmetric reduction approach and the plausible mechanism.
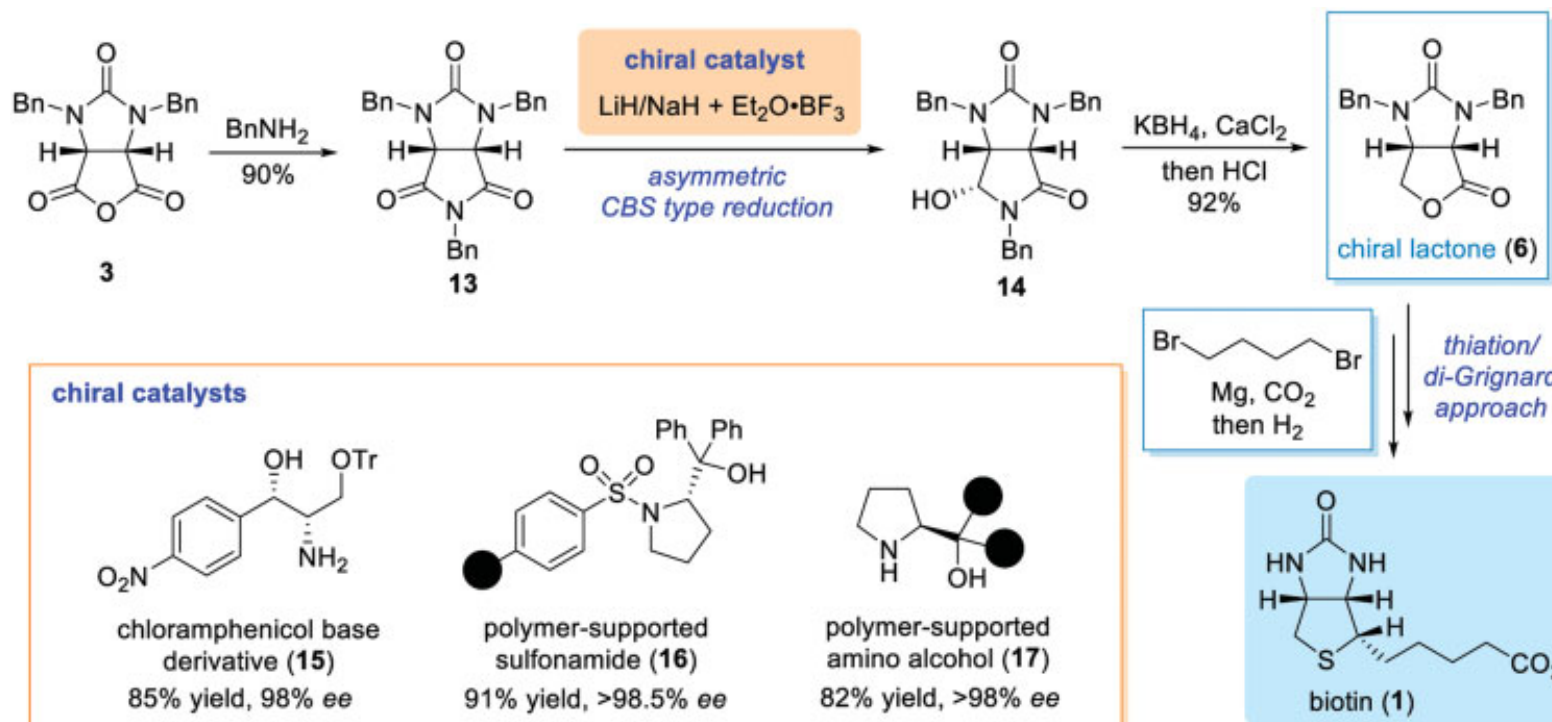

polymer-supported amino alcohol (17) $82 \%$ yield, $>98 \%$ ee

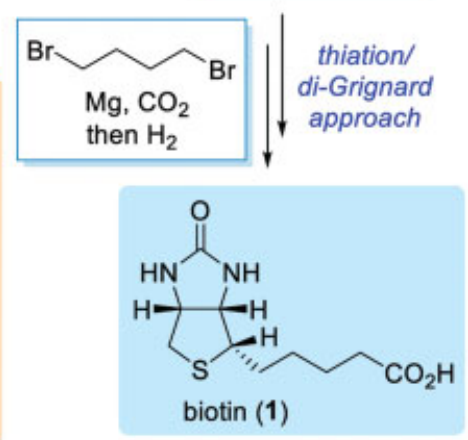

Scheme 4 Chen's oxazaborolidine-catalyzed asymmetric reduction process.

excellent outcome of yields and enantioselectivities (82-91\% yield, $\geq 98 \% e e$ ). The latter underwent further reduction and acid treatment, leading to lactone 6 in 92\% yield, which could readily be converted into biotin through thiation and the subsequent introduction of a C5 side chain using modified di-Grignard approach, with 1,4-dibromobutane and carbon dioxide as the reactants. ${ }^{15 d}$ Thus, this route would be greatly beneficial to the scalable synthesis of biotin.

The enantioselective alcoholysis of meso-cyclic anhydrides is a powerful strategy to conveniently access optically active hemiesters as valuable building blocks for many natural products and biologically active substances. ${ }^{16}$ In particular, Deng, ${ }^{17}$ Song, ${ }^{18}$ Bolm, ${ }^{19}$ Connon, ${ }^{20}$ Chen, ${ }^{21}$ and their coworkers have made numerous impressive progresses in the opening of anhydrides by chiral Lewis bases, as demonstrated by cinchona alkaloids and their derivatives. Toward ongoing pursuit of asymmetric synthesis of biotin, Chen and coworkers developed a novel organocatalytic anhydride desymmetrization strategy (Scheme 5). ${ }^{21,22}$ In this pivotal transformation, two contiguous stereogenic centers were readily established through a rapid chloramphenicol base and cinchona alkaloid catalyzed enantioselective alcoholysis of meso-cyclic anhydride $\mathbf{3}$ to afford hemiesters 18, with excellent yields and enantiomeric excesses (up to 99\% yield, $98.5 \%$ ee). Conversion of hemiesters $\mathbf{1 8}$ to biotin was readily achieved viaa well-known process. Given such highefficiency of the desymmetrization, Chen developed an asymmetric alcoholysis strategy that has great potential for use in the mass production of biotin.

After unremitting efforts and continuous innovation, Chen successfully solved several critical bottleneck reaction problems and key transformations, and developed four new cutting-edge and eco-friendly technologies and processes for the biotin synthesis, including chemical resolution, asymmetric reduction, and asymmetric alcoholysis processes. Indeed, Chen's synthetic methods represent a major breakthrough in 
<smiles>O=C1OC(=O)[C@H]2[C@H]1N(Cc1ccccc1)C(=O)N2Cc1ccccc1</smiles>

3

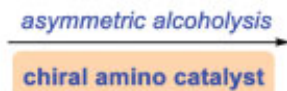

$\mathrm{R}-\mathrm{OH}$

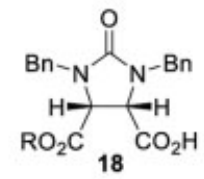

chiral hemiester

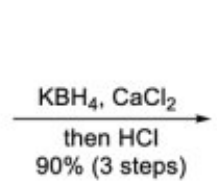

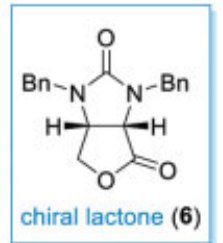

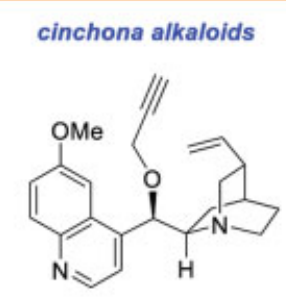

$97 \%$ yield, $88 \%$ ee



$99 \%$ yield, $97 \%$ ee

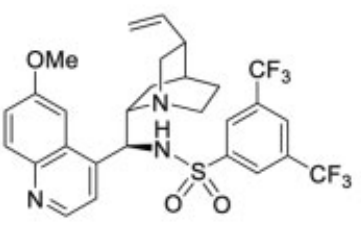

up to $99 \%$ yield, $92 \%$ ee

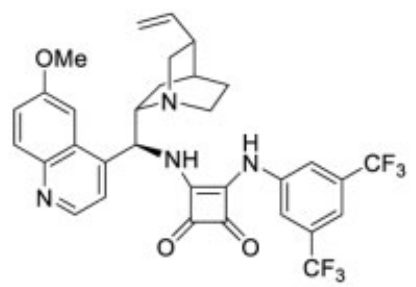

$98 \%$ yield, $96 \%$ ee
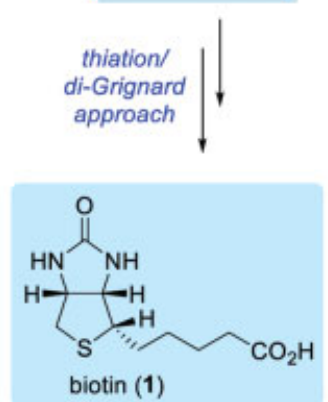

chloramphenicol base derivatives<smiles>[R20]C[C@H]([C@H](O)c1ccc([R7])cc1)N([R3])C</smiles>

up to $88 \%$ yield, $98.5 \%$ ee

Scheme 5 Chen's asymmetric alcoholysis process.

the industrial production of biotin. ${ }^{23}$ Notably, triggered by the endeavors of asymmetric synthesis of biotin, Chen has conducted a deep and extensive research on chloramphenicol base chemistry for decades, achieving a series of significant progresses involving chiral catalysts, chiral auxiliaries, synthetic methodologies, and total synthesis. ${ }^{24,25}$

\section{Revolutionary Artificial Synthesis of Artemisinin}

Each year, hundreds of millions of people are infected with malaria around the world. In 2010 alone, the number of infected people was as high as 200 million, and the number of deaths was as high as 655,000. According to the World Health Organization (WHO), approximately $40 \%$ of world's population is threatened by malaria. Every year, an estimated 350 to 500 million people are infected with malaria, and 3,000 children die every day because of it. ${ }^{26}$

Artemisinin is a natural ingredient used in the effective treatment of malaria. After a team of Chinese scientists successfully extracted it from plants in the 1970s, the development of related drugs was performed. In 2005, artemisininbased combination therapy was recommended by the WHO as the best way to treat malaria. ${ }^{27}$ It is of great medical, economic, and social significance to solve the problem of raw materials for artemisinin production. However, artemisinin antimalarials are in short supply. The international market for artemisinin is approximately 180 tons. Even so, there are still many people who need it for the treatment.

Artemisinin is a kind of terpenoid compound, originally extracted from the plant Artemisia annua (-Fig. 3). The main domestic production method is still extraction from A. annua,



Fig. 3 Plant Artemisia annua.

but the plant occupies cultivated land anddepends on the environment. The production of artemisinin is mainly performed by repeatedly extracting $A$. аnnua $L$. with an organic solvent and purifying and separating it. Among the steps, the leaching step has problems of low selectivity and serious solvent loss, and the purification and separation processes (-Fig. 4) have long processing times and high energy consumption, resulting in limited processing capacity and limited production capacity. Furthermore, the extraction process is cumbersome.

At present, the production of artemisinin still relies mostly on plant extraction. Seventy percent of artemisinin raw materials come from China. In 2006, scientists from Amyris Inc. and the University of California, Berkeley, United States, developed a biological process using engineered yeast for the production of large quantities of artemisinic acid 20 (AA;Scheme 6), ${ }^{28}$ 


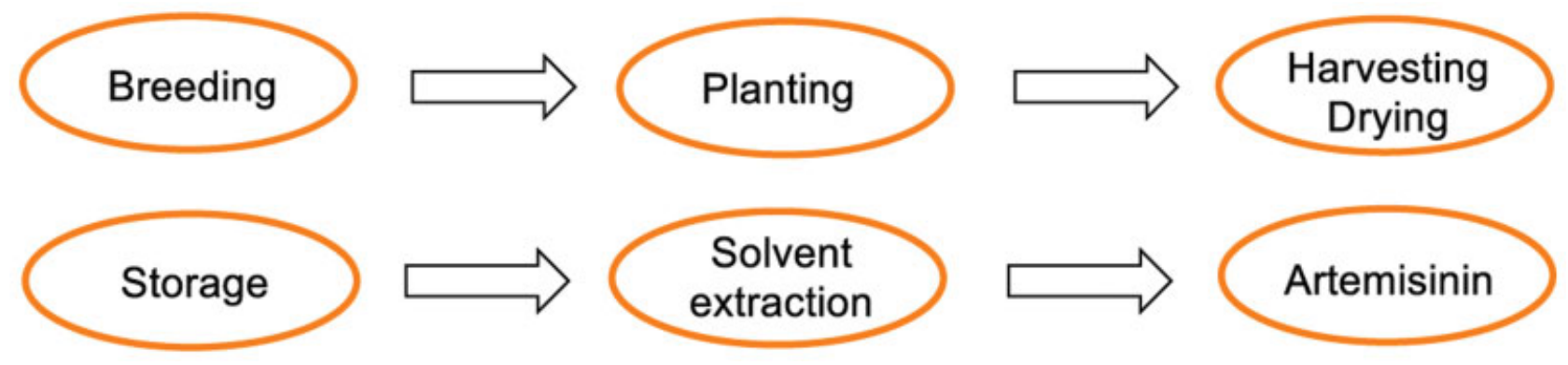

Fig. 4 Artemisinin extraction process.

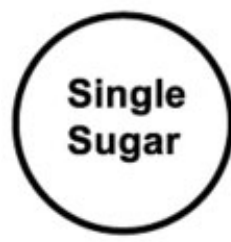

19

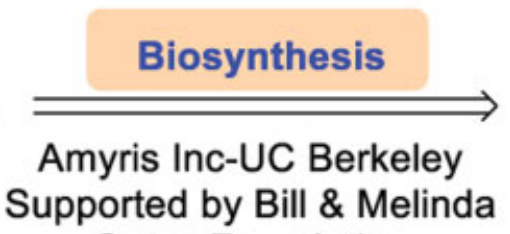

Gates Foundation

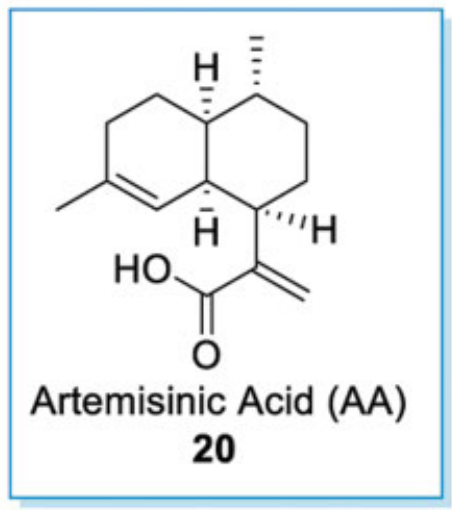

Scheme 6 Biosynthesis of artemisinic acid (AA) by Amyris-UC Berkeley from sugar.

thus, the two remaining challenges are how to convert AA into dihydroartemisinic acid (DHAA) and DHAA into artemisinin.

The transformation of artemisinic acid into artemisinin antimalarials is also far from simple. Artemisinin is a sesquiterpene lactone compound containing a peroxy group. The rare peroxygen is fixed and connected with two quaternary carbon atoms, forming a bridge. The full synthesis of this peculiar structure is extremely challenging. ${ }^{29}$

In 2011, Wu and colleagues reported the synthesis of artemisinin in the absence of light from artemisinic acid. ${ }^{30}$ The process was performed at room temperature to obtain artemisinin ina total yield of $41 \%$ in 2013 , using an improved synthetic technology (Scheme 7). ${ }^{31}$

The research team led by Zhang, at the School of Chemistry and Chemical Engineering, Shanghai Jiao Tong University (SJTU), finally developed a conventional and practical asym- metric hydrogenation synthesis method for (R)-DHAA 21 (Scheme 8), a key intermediate for artemisinin. ${ }^{32}$

In 2005, Zhang led a team that converted artemisinic acid into ( $R$ )-DHAA 21, and then used a specific catalyst they developed to allow efficient production of DHAA through a conventional reaction device without a photochemical reaction, which is often less effective. Finally, artemisinin was obtained in high yield by oxidative rearrangement. In 2012, they developed a chemical synthesis method that does not require the use of light to further increase the synthesis efficiency of artemisinin. This was a major advance made by Chinese scientists in the field of high-efficiency synthesis of artemisinin, which will make large-scale production of artemisinin a reality (Scheme 9). ${ }^{33}$

From 2012 to 2016, Zhang and coworkers worked diligently to industrialize this technology. They achieved a<smiles>CC1=CC2C(CC1)[C@H](C)CC[C@H]2[C@@H](C)C(=O)O</smiles>

21

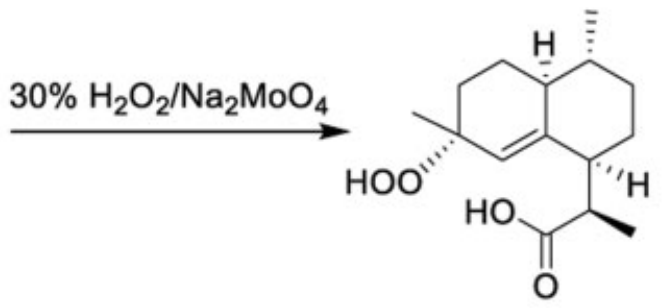

22
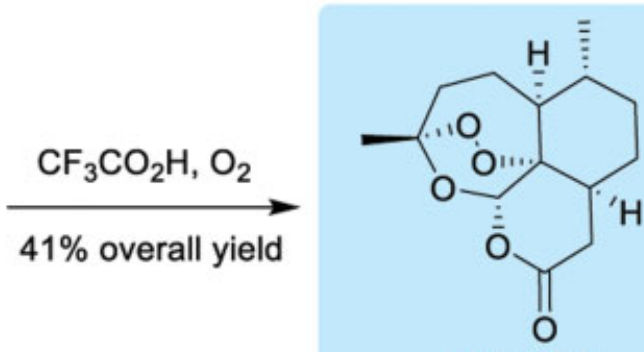

artemisinin

23

Scheme 7 Wu's approach to the synthesis of artemisinin. 
<smiles>C=C(C(=O)O)C1CC[C@@H](C)[C@H]2CCC(C)=CC12</smiles>

20

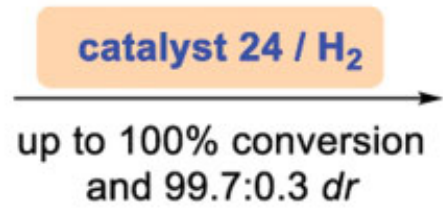

21

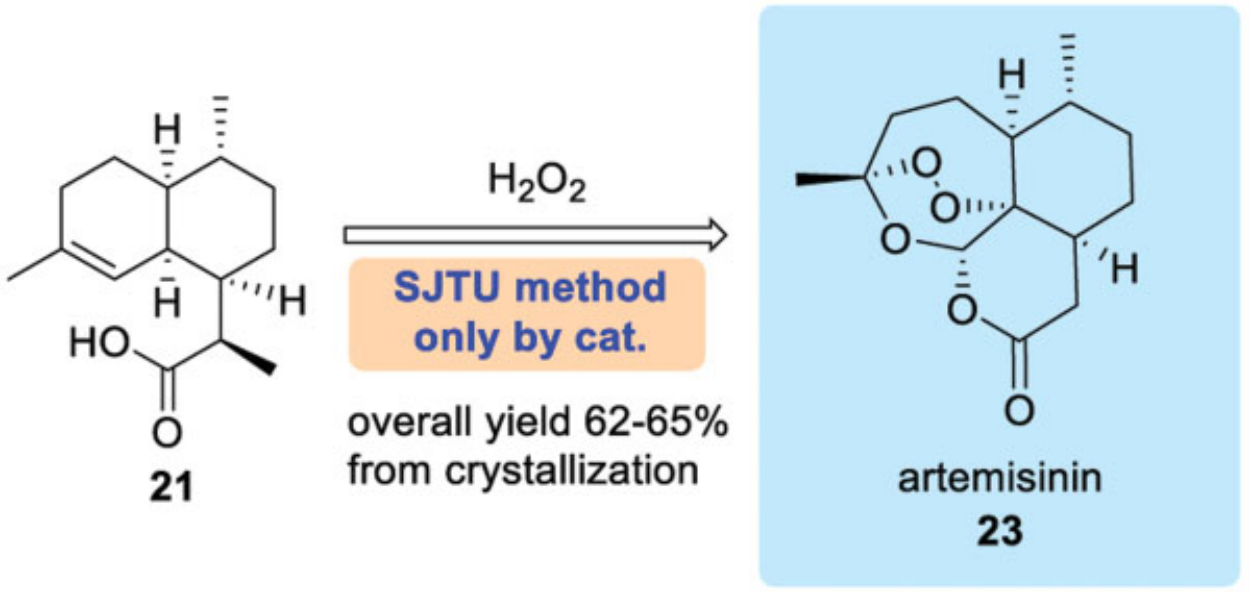
from crystallization

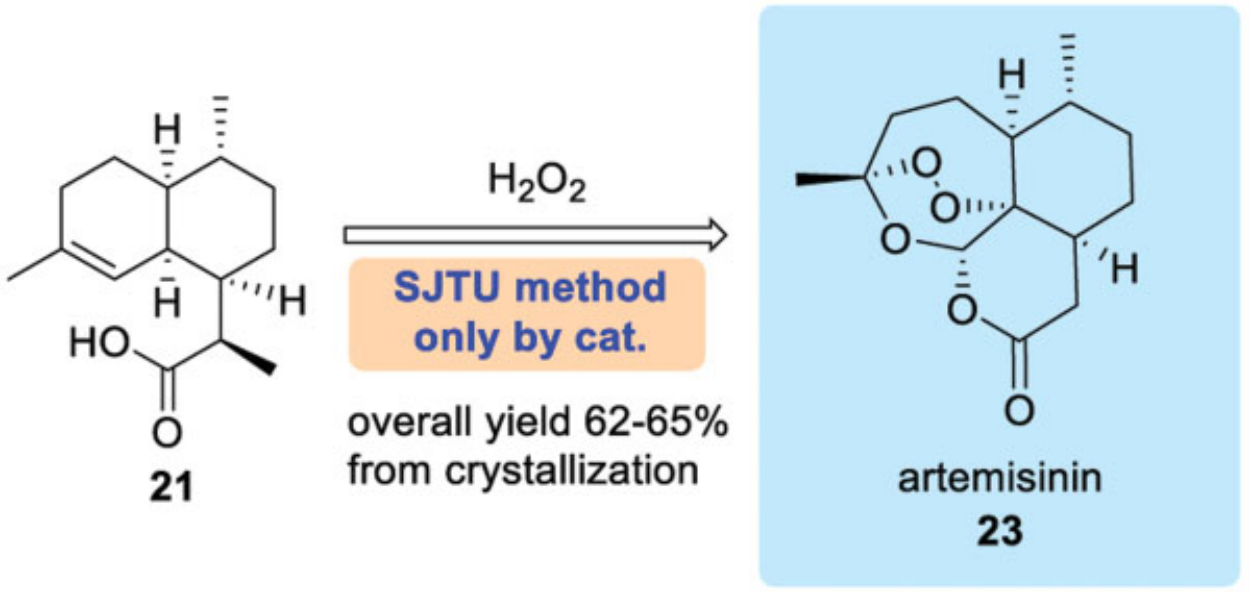

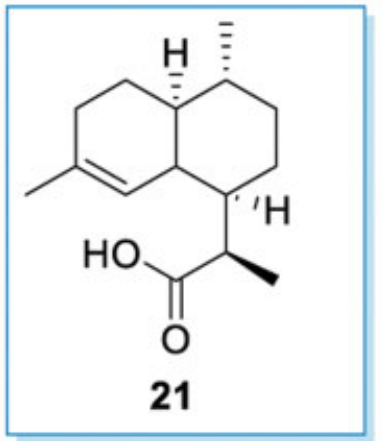

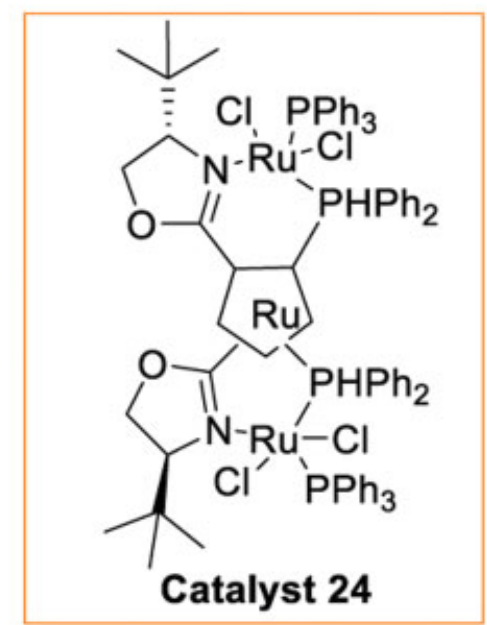

Scheme 8 Zhang's conventional and practical asymmetric hydrogenation synthesis of (R)-DHAA 21.

Scheme 9 Zhang's key reaction in the revolutionary artificial synthesis of artemisinin.

smooth 30- to 500-L (multikilogram) scale-up or pilot synthesis, making a low-cost artemisinin supply a reality. For the first time, the high-efficiency synthesis of the antimalarial drug artemisinin was made possible, and artemisinin is expected to achieve large-scale industrial production by Shanghai Fosun Pharmaceutical (Group).

\section{Scalable Total Synthesis of Antitumor Marine Nature Product Trabectedin (ET-743)}

The first marketed modern marine drug for the treatment of soft tissue sarcoma was trabectedin 31 (ET-743). ${ }^{34}$ Its analogues are undergoing phase III clinical studies for the treatment of small-cell lung cancers. Current production requires the use of another rare natural product, tunicate, which can only generate $1.0 \mathrm{~g}$ of ET-743 from 1.0 ton of tunicate via semisynthesis, requiring 21 steps of reaction with only $1 \%$ total yield. ${ }^{35}$ The market price of the drug substance is $>\$ 10,000 / g$. Over the past 20 years, four routes have been developed for the total synthesis of ET-743 from readily available raw materials, ${ }^{36-39}$ but the total number of steps for each route isall above 40 , contributing to their low overall yield and preventing scale-up for industrial production.
In 2019, Maand coworkers at Shanghai Institute of Organic Chemistry (SIOC) developed a novel, highly efficient, and practical total synthesis method of ET-743 from Cbz-protected (S)-tyrosine. ${ }^{40}$ This new synthetic method delivers a $1.6 \%$ overall yield in 26 total steps, with a light-mediated remote $\mathrm{C}-\mathrm{H}$ bond activation to assemble a benzo[1,3]dioxole-containing intermediate $\mathbf{2 7}$ (Scheme 10). This new method is one-third shorter than the original synthetic route and can be conveniently scaled up. The process and related technologies have been licensed and transferred to a Chinese pharmaceutical company and will make a positive contribution to cancer therapy.

\section{Cu(I)/Oxalic Diamide Catalyzed Coupling Reaction and Its Application in Pharmaceutical Processes}

Ma and coworkers at SIOC first developed the amino acidpromoted Ullmann coupling reaction, ${ }^{41}$ a reaction that has been applied thousands of times in the synthesis and development of functional molecules (Scheme 11). ${ }^{42}$ The application includes a ton-scale production for the antihypertensive drug perindopril 41 (Scheme 12), ${ }^{43}$ intermediates by DSM and tons of production for Xiidra (Lifitegrast) 44 (Scheme 13), ${ }^{44}$ a treatment of signs and symptoms of dry-eye disease by Shire, 

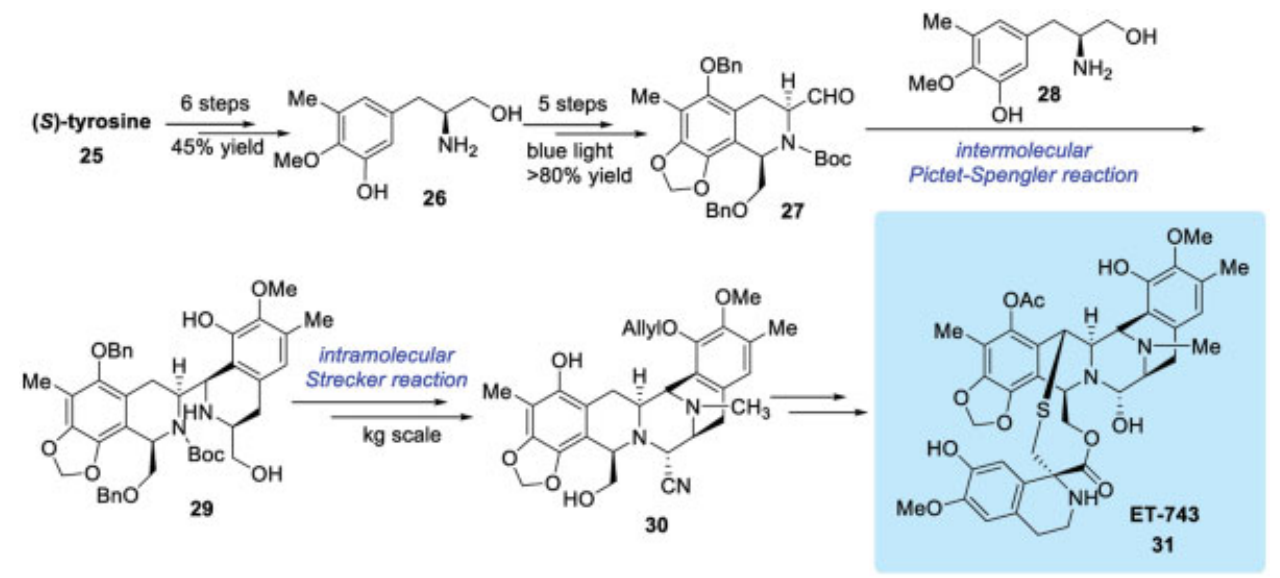

Scheme 10 Scalable total synthesis of antitumor marine nature product trabectedin (ET-743).

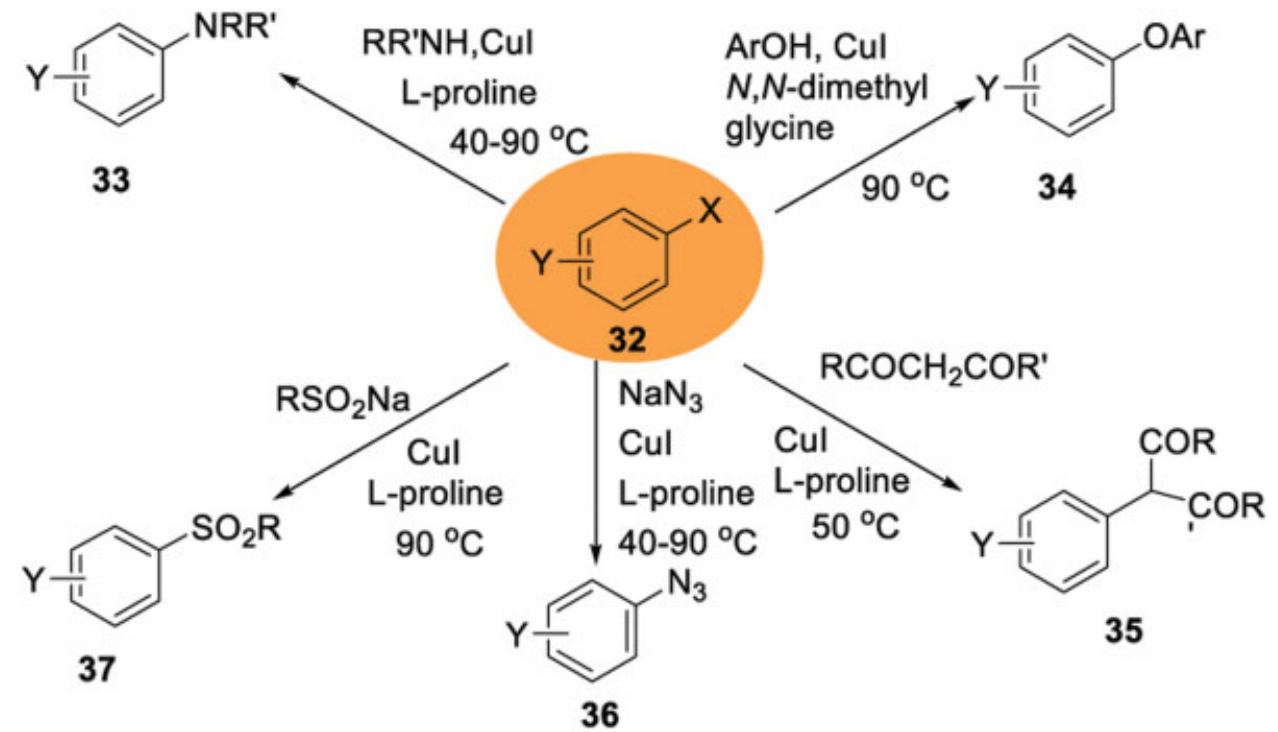

Scheme 11 Ma's amino acid-promoted Ullmann coupling reaction.<smiles>[X]c1ccccc1/C=C/C(=O)O</smiles><smiles>[X]=[Bi]Cl</smiles>

38<smiles>[X]c1ccccc1C[C@H](N)C(=O)O</smiles>

39<smiles>CC#CC</smiles>

40

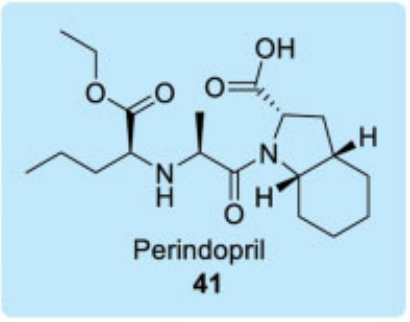

Scheme 12 Ton-scale production of intermediates for perindopril.

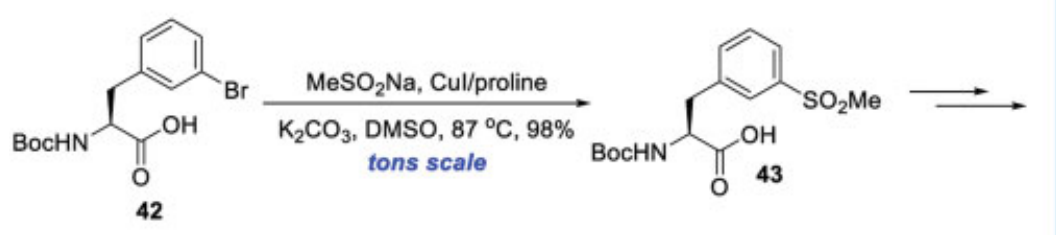<smiles>COS(=O)(=O)c1cccc(CC(NC(=O)c2c(Cl)cc3c(c2Cl)CCN(C(=O)c2ccc4ccoc4c2)C3)C(=O)O)c1</smiles>

Scheme 13 Tons-scale production of Xiidra (Lifitegrast) under Ma's conditions. 

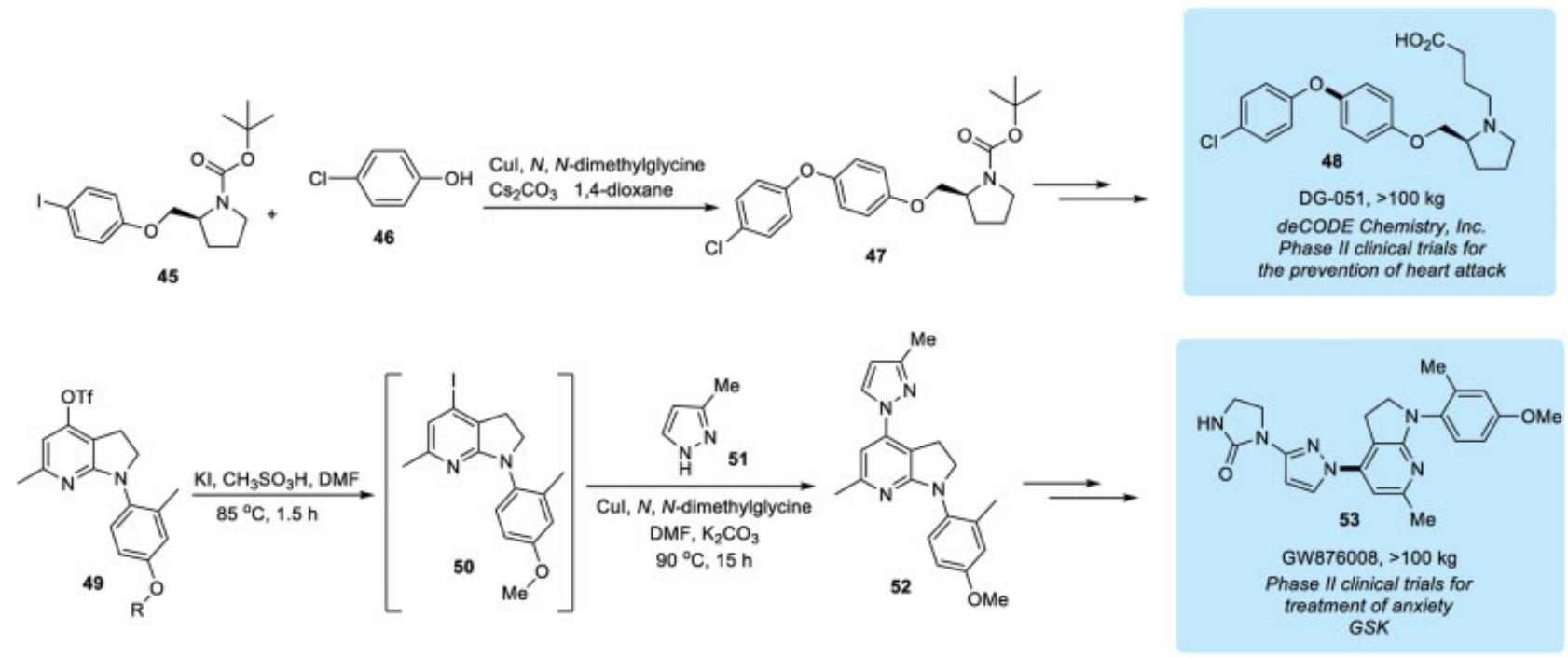

Scheme 14 Synthesized drug candidates via the amino acid-promoted Ullmann coupling.

and two other drug candidates $\mathbf{4 8},{ }^{45}$ at phaselI clinical trials for the prevention of heart attack, and $\mathbf{5 3},{ }^{46}$ at phasell clinical trials for the treatment of anxiety (Scheme 14).

Aryl sulfone has been one of the top fivemost frequently used scaffolds in drug structures based on statistics of approximately 7,000 Food and Drug Administration (FDA)approved drugs and experimental drugs. The classical method for preparing aryl sulfones is the direct sulfonylation of arenes, and in the late stage of manipulation it gives unsatisfactory regioselectivity and poor functional group tolerance. Ma's amide ligand 55, HMNPC, derived from 4-hydroxy-Lproline and 2-methylnaphthalen-1-amine, is an excellent and highly practical ligand for Cul-catalyzed direct coupling of (hetero)aryl halides with sulfinic acid salts under mild conditions. ${ }^{47}$ The reaction proceeds at room temperature

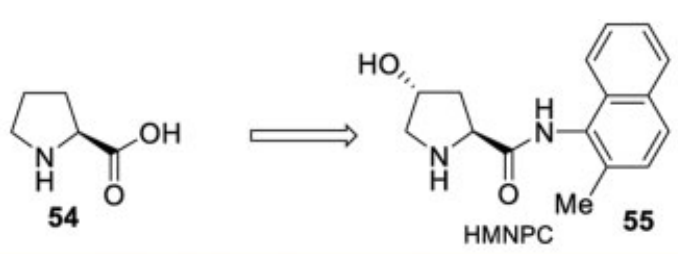

\begin{tabular}{|c|c|}
\hline \multicolumn{2}{|c|}{ First example for metal-catalyzed coupling of $\mathrm{ArCl}$ with $\mathrm{MeSO}_{2} \mathrm{Na}$} \\
\hline \multirow[b]{2}{*}{ (hetero) $\mathrm{ArCl}+\mathrm{MeSO}_{2} \mathrm{Na}$} & $\begin{array}{l}10 \mathrm{~mol} \% \mathrm{Cul} \\
10 \mathrm{~mol} \% \mathbf{5 5} \\
\end{array}$ \\
\hline & $\begin{array}{l}\mathrm{K}_{3} \mathrm{PO}_{4}, \mathrm{DMSO} \\
120^{\circ} \mathrm{C}, 24 \mathrm{~h}\end{array}$ \\
\hline \multirow[b]{2}{*}{ (hetero) $\mathrm{ArBr}+\mathrm{RSO}_{2} \mathrm{Na}$} & $\begin{array}{l}2-5 \mathrm{~mol} \% \mathrm{Cul} \\
2-5 \mathrm{~mol} \% \mathbf{5 5}\end{array}$ \\
\hline & $\begin{array}{l}\mathrm{K}_{3} \mathrm{PO}_{4}, \mathrm{DMSO} \\
90^{\circ} \mathrm{C}, 24 \mathrm{~h}\end{array}$ \\
\hline \multicolumn{2}{|c|}{$\begin{array}{l}\text { First example of Cu-catalyzed arylation at both room temperature } \\
\qquad \text { and low catalytic loading }\end{array}$} \\
\hline \multirow{2}{*}{ (hetero) $\mathrm{Arl}+\mathrm{RSO}_{2} \mathrm{Na}$} & $\begin{array}{l}1 \mathrm{~mol} \% \mathrm{Cul} \\
1 \mathrm{~mol} \% 55 \\
\end{array}$ \\
\hline & $\begin{array}{l}\mathrm{K}_{3} \mathrm{PO}_{4}, \mathrm{DMSO} \\
\mathrm{rt}, 24 \mathrm{~h}\end{array}$ \\
\hline
\end{tabular}

Scheme 15 Cul-catalyzed direct coupling of (hetero)aryl halides with sulfinic acid salts. with only $0.5 \mathrm{~mol} \% \mathrm{CuI}$ and the ligand, representing the first example for Cu-catalyzed arylation with a low catalytic loading underroom temperature conditions (Scheme 15).

For the first time in 2015, Ma and coworkers discovered a much more effective oxalyl diamine ligand which achieved a copper-catalyzed coupling reaction of an inexpensive aryl chloro compound under mild conditions, ${ }^{48}$ coupling aryl bromide and iodide with very low catalyst loading (Scheme 16). Under these milder and more practical conditions, thisuseful method is expected to be applied to a large-scale production, and more than 10 different APIs and bulk drugs or key intermediates have been prepared or are under preparation by a jointventure in China using this technology (CE PHARM).

It is undeniable that, over the past three decades, palladium-catalyzed C-C cross-coupling reactions, e.g., Suzuki coupling, Negishi coupling, the Heck reaction, and Pd-catalyzed $\mathrm{C}-\mathrm{N}, \mathrm{C}-\mathrm{O}$, and $\mathrm{C}-\mathrm{S}$ formations, have changed synthetic organic chemistry dramatically. However, from the perspective of economic and sustainable development, under the same circumstances, if a cheaper copper catalyst is capable of carrying outa similar transformation yielding comparable experimental results while avoiding harsh experimental conditions, process chemists will prefer to use the coppercatalyzed reactions. The competition between copper and palladium over the past two decades can be traced to a new systematic study of $\mathrm{Cu}$ /oxalic diamide ligands (from 2013 to 2018;-Fig. 5), and copper-catalyzed coupling reactions will find broader applications at academic laboratories and in the pharmaceutical industry.

\section{Chiral Bicycle Imidazole Nucleophilic Catalyst (R-DPI) for Biologically Active Protide Prodrugs}

In 2017, DiRocco and coworkers at Merck, United States, published their latest research on stereoselective phosphorylation ${ }^{49}$ for the high-efficiency synthesis of the phase III clinical new nucleoside prodrug 63, MK-3682 (Scheme 17). Their work is based on the original work of Zhang on chiral 
56

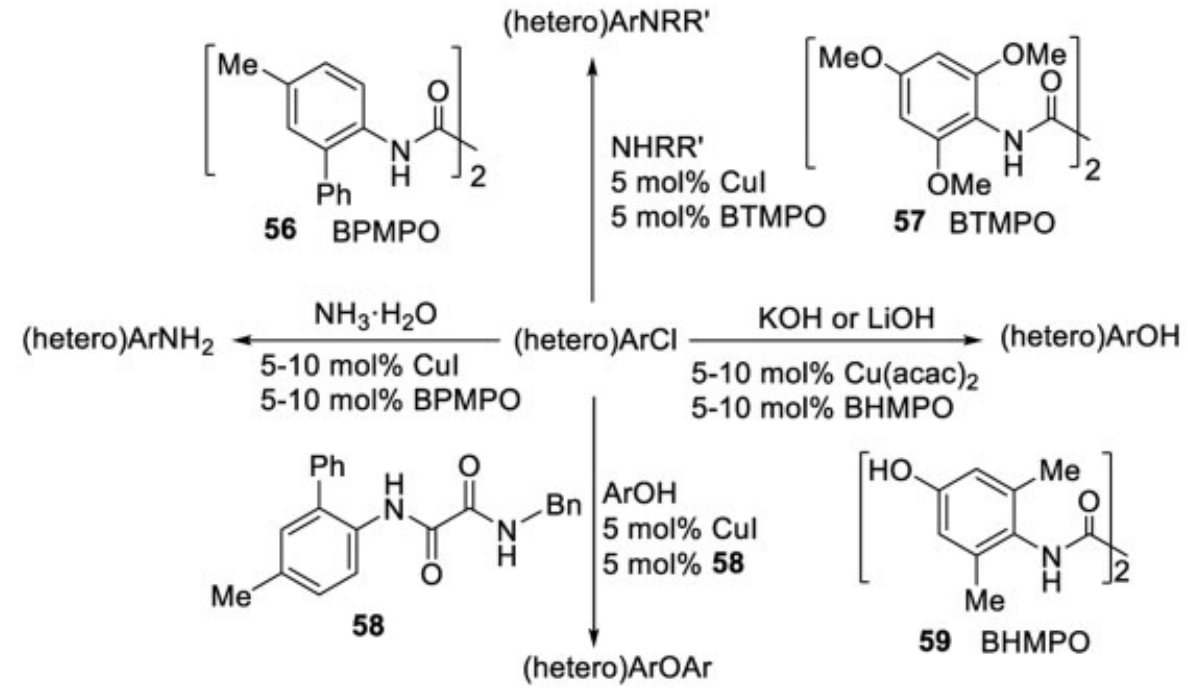
(hetero)ArNRR'

Scheme 16 Highly effective oxalyl diamine ligand/copper-catalyzed coupling reaction of aryl chloro compounds.

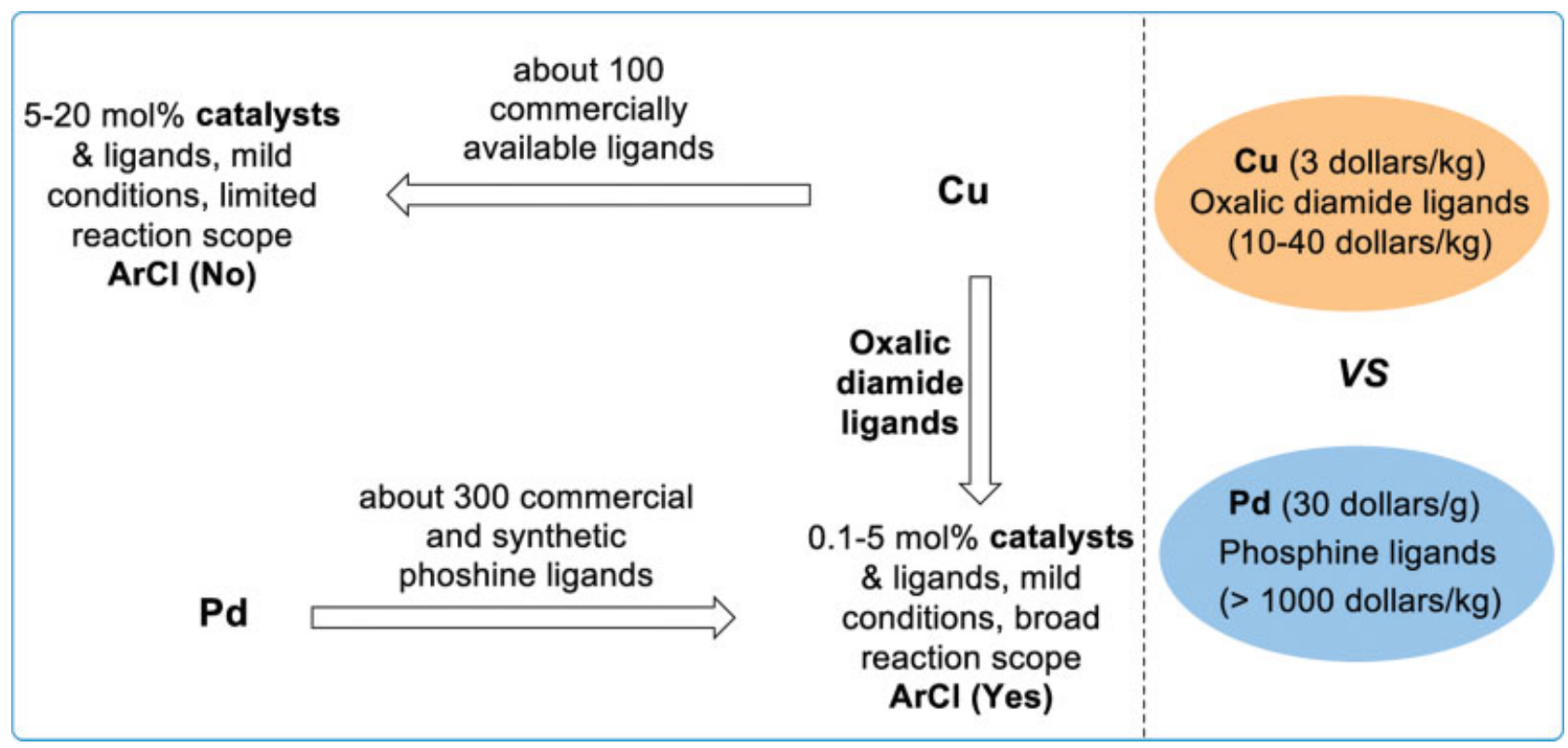

Fig. 5 Cu versus Pd, a 20-year competition in catalyzing C-X coupling.<smiles>[Y6]C(NP(=O)(Cl)Oc1ccccc1)C(=O)OCCC</smiles>

61

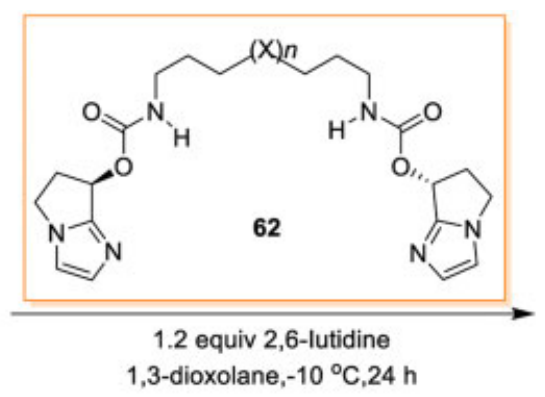

1,3-dioxolane,-10 ${ }^{\circ} \mathrm{C}, 24 \mathrm{~h}$

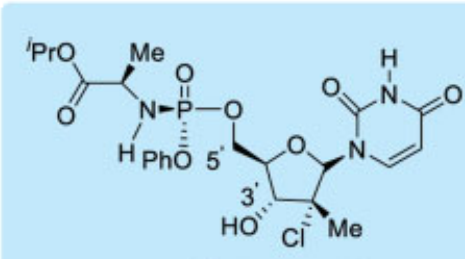

63 (MK-3682)

Scheme 17 Chiral imidazole catalyst (R-DPI) for protide prodrug MK-3682. 

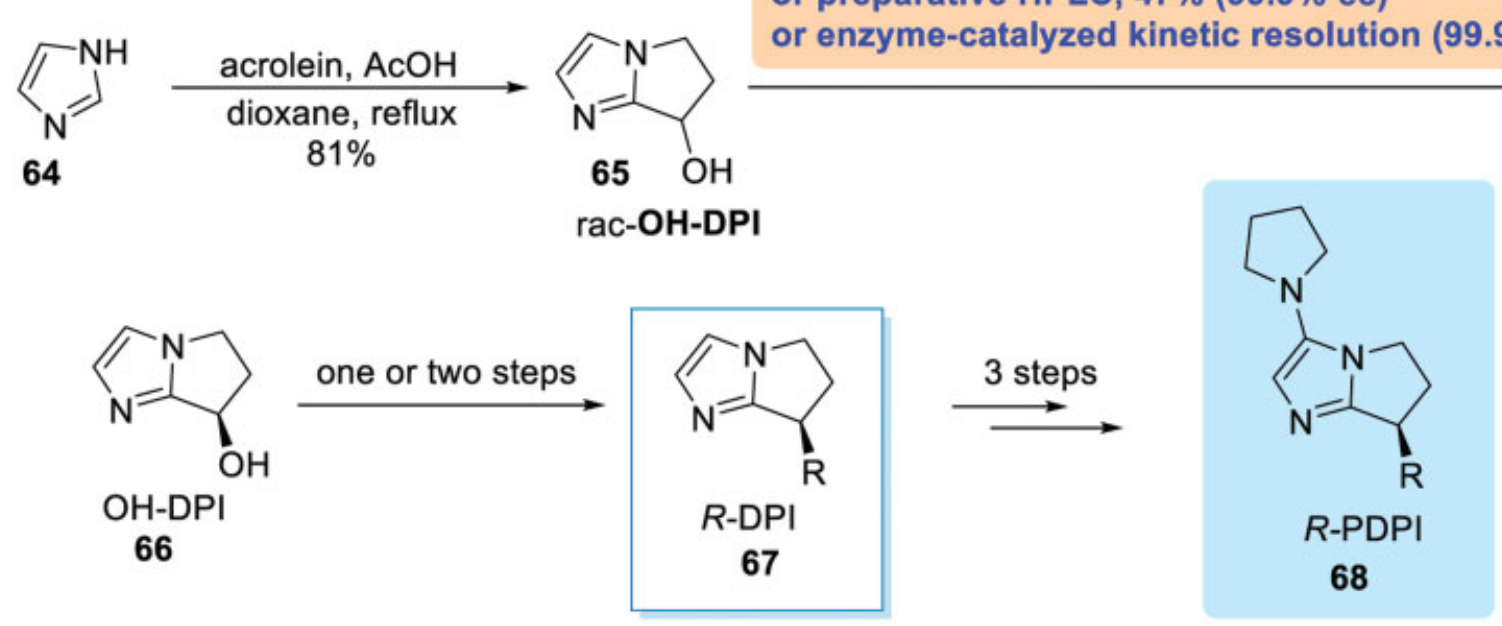

Scheme 18 Synthesis of chiral bicyclic imidazole catalyst $R$-DPI and related $R$-PDPI derivative.

bicyclic imidazole framework catalysts, ${ }^{50,51}$ in which he designed and synthesized a multifunctional catalyst with a chiral bicyclic imidazole skeleton, which achieved asymmetric synthesis of nucleoside with high stereoselectivity and high yield. Compared with the existing small-molecule catalysts, the chiral bicyclic imidazole catalyst skeleton introducedby Zhang's team can be constructed in high yield viaa one-step reaction of inexpensive imidazole and acrolein, which can be easily prepared on a large industrial scale (Scheme 18). ${ }^{52}$

\section{Chiral Catalysts for Asymmetric Synthesis of Silodosin, (S)-Duloxetine, and Bulk Drugs}

In China, research on asymmetric synthesis of chiral molecules has seen significant improvement in the past decade, with the achievement of excellent research results ${ }^{53-55}$; however, their application in the pharmaceutical industry still needs development. First, the main limitation of catalytic chiral technology is the turnover number of the catalyst. Generally speaking, catalysts with a turnover number of more than 10,000 in the laboratory are valued for further industrialization. Second, a secondary limitation on catalytic chiral technology in industry is its strict reaction conditions, which cannot be too harsh and must be suitable for industrial use. Third, the requirements for the scale-up or production using this technology must be safe and environmentally friendly. Fourth, the cost of the catalyst cannot be too high. Finally, the pharmaceutical company's own R\&D unit and process optimization capabilities should be able to adopt and utilize the new technology, which has also been a key issue. ${ }^{56}$

In asymmetric catalysis studies, chiral phosphorus ligands have been widely used, and many highly efficient chiral phosphorus ligands have been reported. However, since a chiral ligand or chiral catalyst is usually only effective for one reaction or one type of substrate, there are still many chiral compounds that lack effective enantioselective synthesis methods. Therefore, the development of new and effective chiral ligands and catalysts is still one of the central tasks of asymmetric catalysis research. In his research, Zhou of Nankai
University found that the chiral spirobiindane structure is an ideal chiral skeleton. It has strong structural rigidity and a stable configuration. The series of chiral ligands (Scheme 19) derived from the skeleton have been widely used in metal catalysis and organic small-molecule catalysis. ${ }^{57}$

By using the novel Ir-SIPHOX catalyst (Scheme 20), process chemists at Zhejiang Jiuzhou Pharmaceutical accomplished the first asymmetric synthesis of silodosin with high efficiency $(S / C=6,000)$ and high enantioselectivity (97\% ee) viaa new approach in which the key transformation is the asymmetric hydrogenation of an unsaturated carboxylic acid intermediate. $^{58}$

Using the electron-donating and rigid P-stereogenic bisphospholane ligand DuanPhos, Zhang at Chiral Quest developed a concise process for the preparation of $(S)$-duloxetine $\mathbf{8 9}$, and asymmetric hydrogenation generated chiral alcohol $\mathbf{8 8}$ with excellent results $(S / C=10,000,>99 \% e e)$, reducing the total cost by $74 \%$ and wastewater by $84 \%$ compared with its original route (Scheme 21) ${ }^{59}$ Founded in 2008 and utilizing Zhang's chiral catalysts, Chiral Quest has developed more than 20 new process routes in scale-up, generating hundreds of tons of pharmaceutical intermediates for $(S)$-duloxetine (for treatment of major depressive disorder), Ramipril (for hypertension), Sitagliptin (for diabetes), and commodity chiral 3-amino1-butanol (50 tons/year).

\section{Eco-Friendly Process for Praziquantel}

Praziquantel 99 is an antiparasitic drug developed in 1980 by Bayer and Merck KGaA. Since its introduction, praziquantel has become a special drug against various worms such as schistosomes due to its high efficiency, low toxicity, wide antiparasitic spectrum, and convenient oral administration. It is also widely used in the treatment of parasitic diseases inanimals. The synthetic route of praziquantel reported by the original company is shown in Scheme $22 .{ }^{60}$

The route used isoquinoline $\mathbf{9 0}$ as a starting material, reacting it with benzoyl chloride and potassium cyanide to obtain compound 92, and then compound 93 by high- 


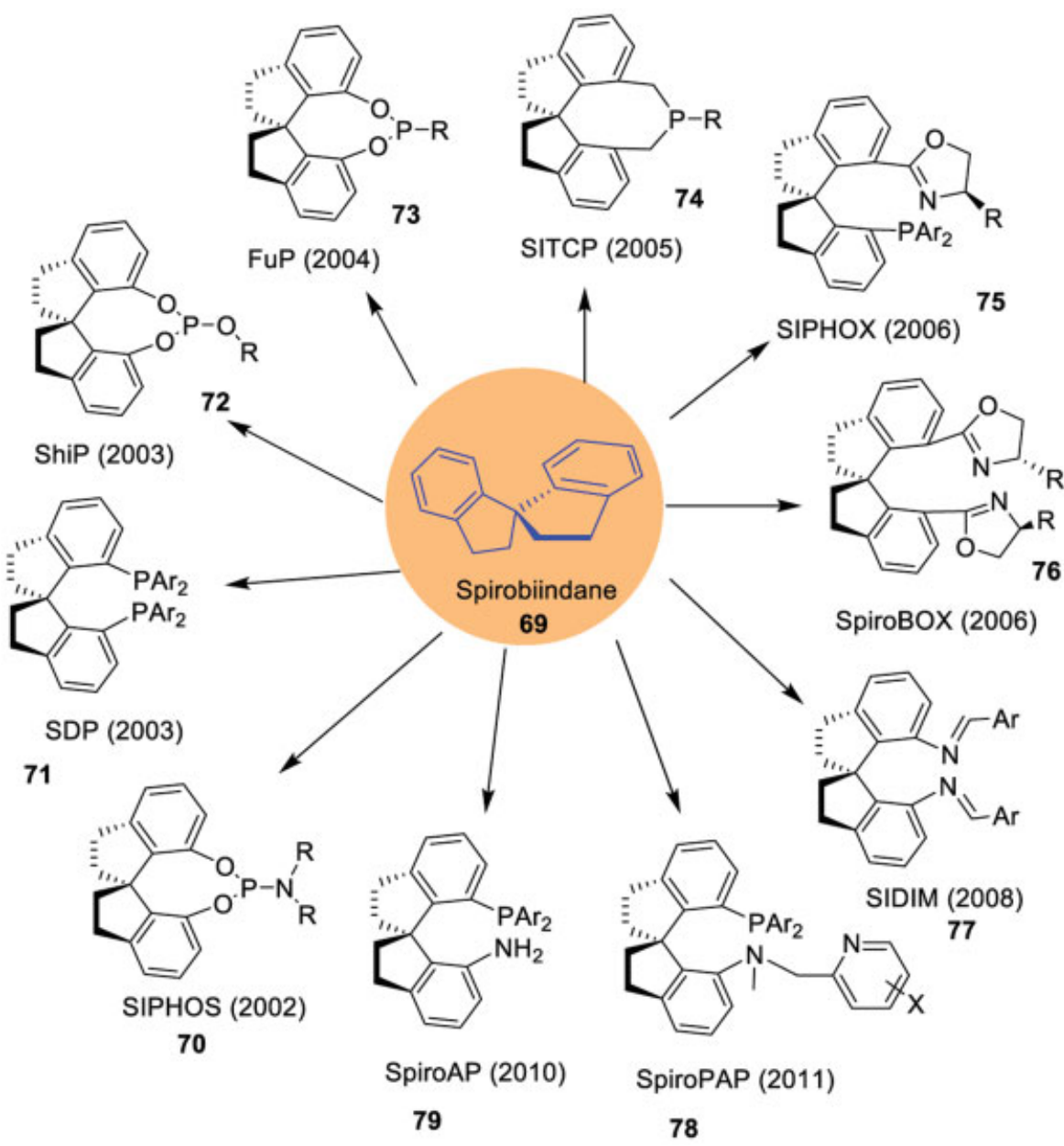

Scheme 19 The series of chiral ligands derived from chiral spirobiindane structure.
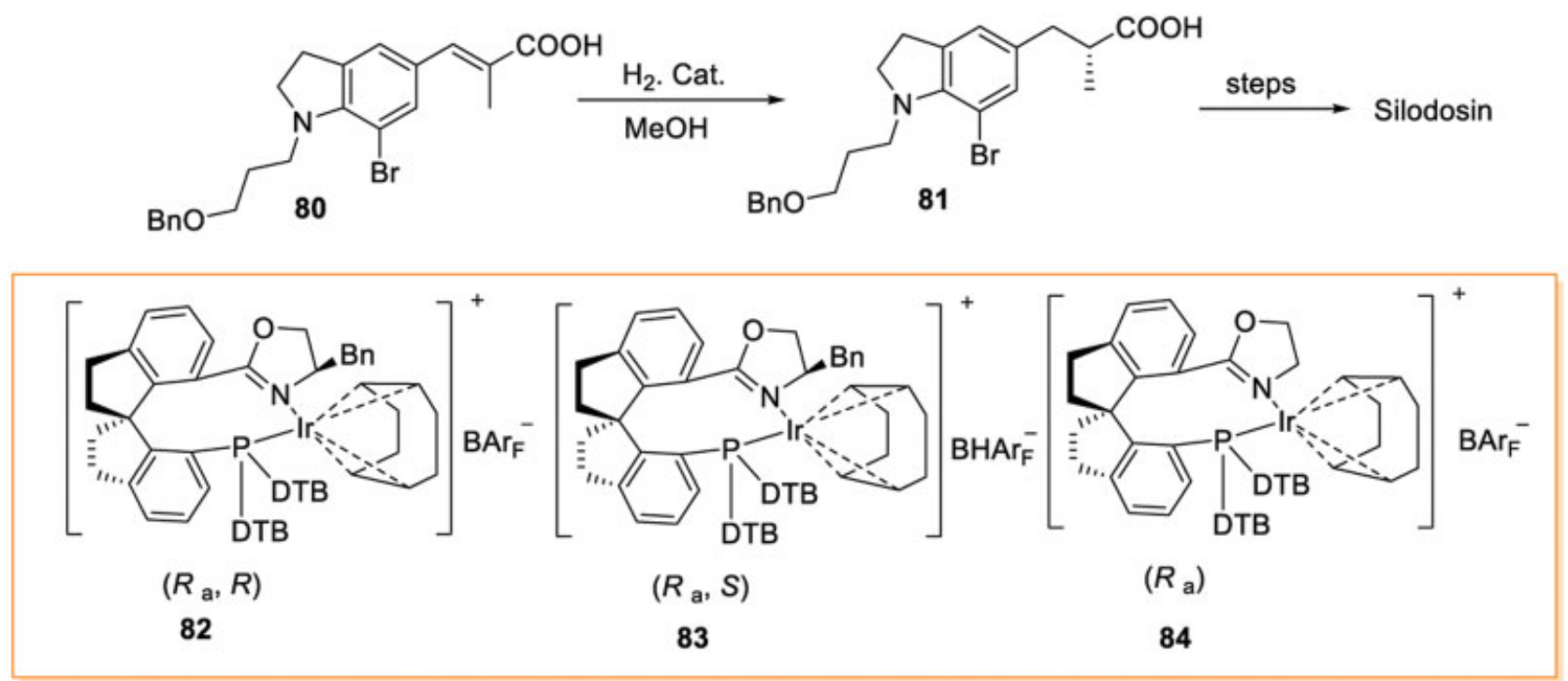

Scheme 20 Asymmetric hydrogenation of unsaturated carboxylic acid intermediate.

pressure (150 atm) hydrogenation reduction. Compound 96 is produced in two steps, and then concentrated phosphoric acid is used to convert it to $\mathbf{9 7}$, before it is finally reacted with benzoyl chloride to obtain the target compound. For decades, praziquantel bulk drug manufacturers have adopted this approach.

However, Zhang realized that there are many shortcomings in this process route, such as the use of a large amount of 


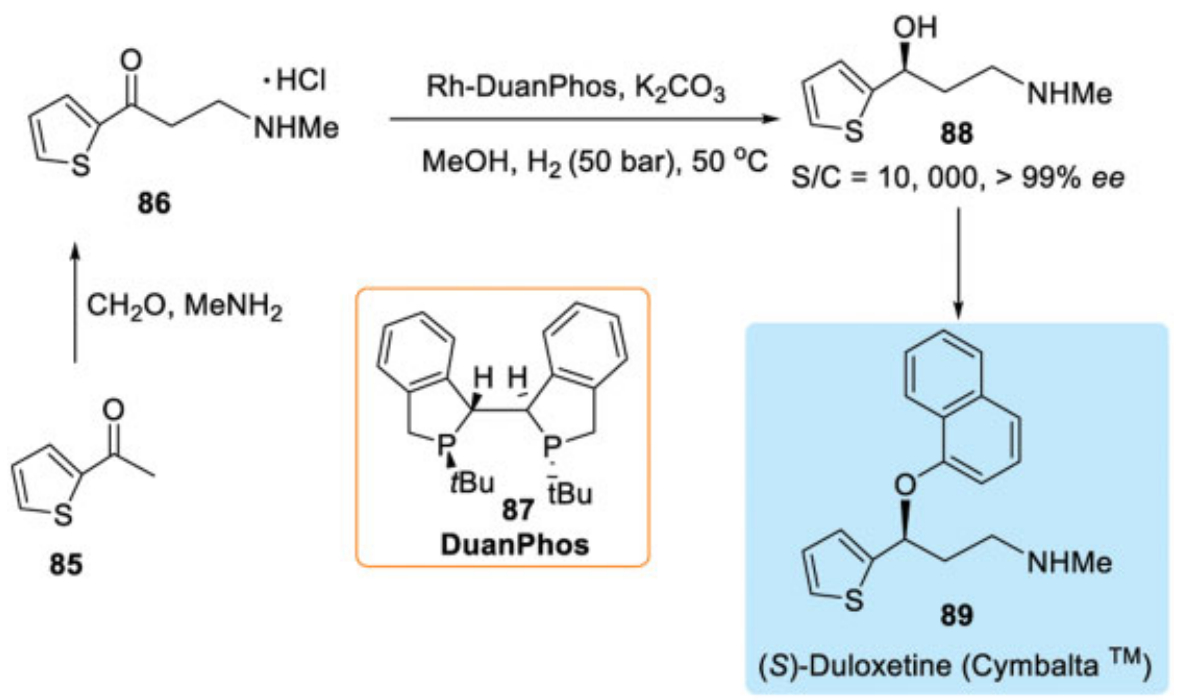

Scheme 21 The preparation of (S)-duloxetine via asymmetric hydrogenation.

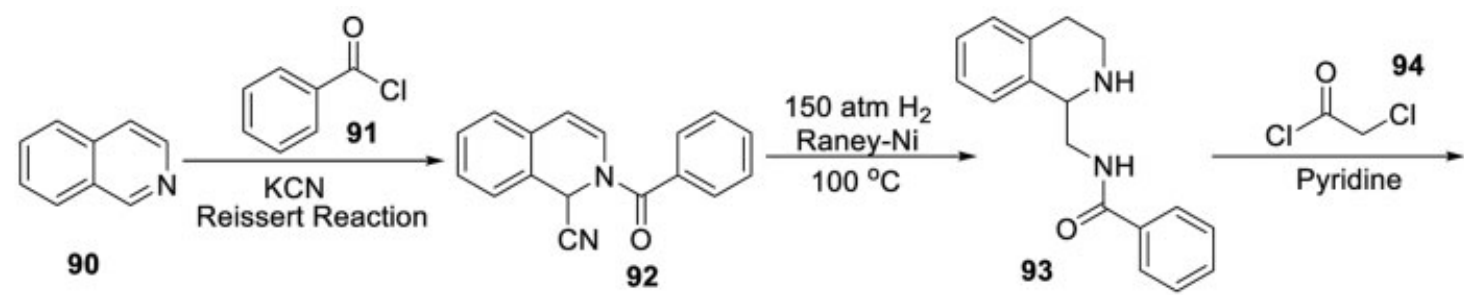<smiles>C/C=C\C(=O)OCC</smiles>

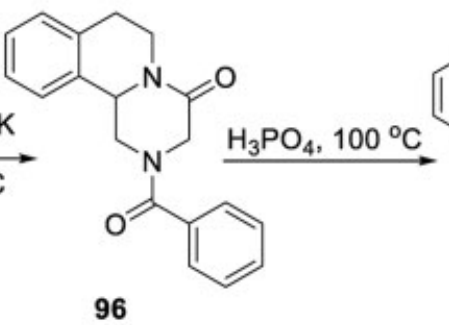<smiles>CCN(C)C1CCCC(C(=O)Cl)C1</smiles>

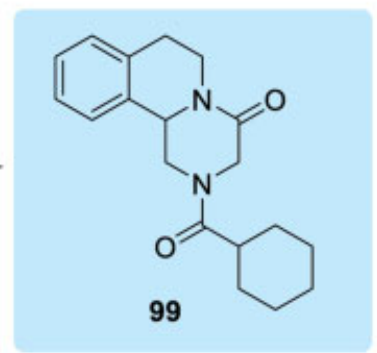

Scheme 22 The original synthetic route of praziquantel by Bayer and Merck KGaA.

highly toxic potassium cyanide, as well as high-temperature and -pressure (150atm) conditions. In addition, the use of concentrated phosphoric acid inevitably leads to eutrophic water pollution. According to statistics, for every 500 tons of praziquantel produced, 310 tons of potassium cyanide are used, and phosphoric acid waste liquid reaches up to 2,430 tons (-Fig. 6). This obviously cannot meet the current environmental protection policy requirements and does not conform to green chemistry principles. In response to these problems, Zhang and his team invented the production process of praziquantel via a well-designed and novel synthetic route, as shown in Scheme $23{ }^{61}$

The new route successfully avoids the extensive use of highly toxic potassium cyanide and phosphoric acid, and cleverly bypasses high-temperature and -pressure conditions. The new process not only drastically reduces the generation of large amounts of waste, but also reduces production costs to half of that of the original process. The new route has achieved a production scale of 100 tons.

\section{Effective Preparation of Active Pharmaceutical Ingredients and Key Intermediates}

In recent years, the use of enzymes and biocatalytic reactions to carry out pharmaceutical processes in industry has become a very important direction for greening scaled-up reactions. The chiral intermediate (3R)-3-aminoazepane is a key motif in the bacterial conjunctivitis antibiotic besifloxacin and in the antitumor clinical drug nazartinib, an estimated glomerular filtration rate (EGFR) antagonist. According to retrosynthetic analysis, the intermediate (3R)-3-aminoazepane $\mathbf{1 0 6}$ is the key raw material for the synthesis of both drugs. Although there are three known synthetic methods (Scheme 24), ${ }^{62}$ they face some shortcomings and flaws. Method A uses nonnatural amino acids as raw materials, requires low-temperature operation, and lactamization results in serious racemization. On the other hand, the final amide reduction on scale is very challenging and difficult, and safe production and reduced environmental pollution are not guaranteed. The starting material used in method $\mathrm{B}$ is expensive and sodium azide is 


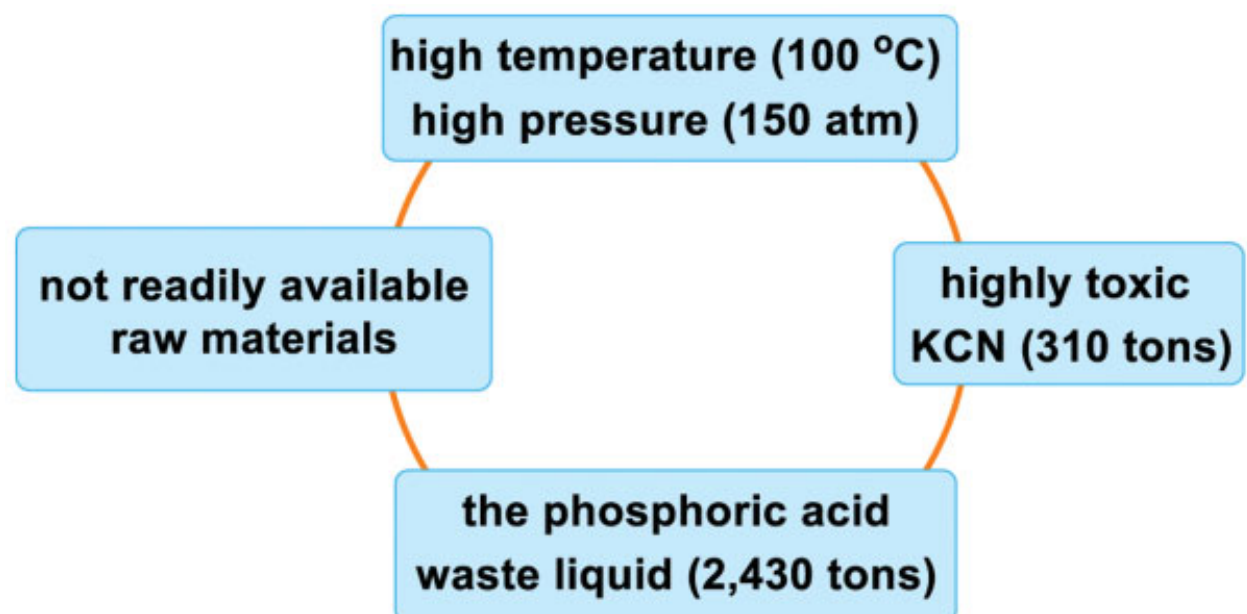

Fig. 6 The footprint when 500 tons of praziquantel is produced.<smiles>CC(C)(C)C1CC(=O)N(Cc2ccccc2)CC(=O)N1CCc1ccccc1</smiles><smiles>CC(C(=O)N1CCc2ccccc2C1CNC(=O)[O-])C1CCC(C(=O)Cl)CC1</smiles><smiles>O=C(C1CCCCC1)N1CC(=O)N2CCc3ccccc3C2C1</smiles>

Scheme 23 Novel production process for praziquantel.

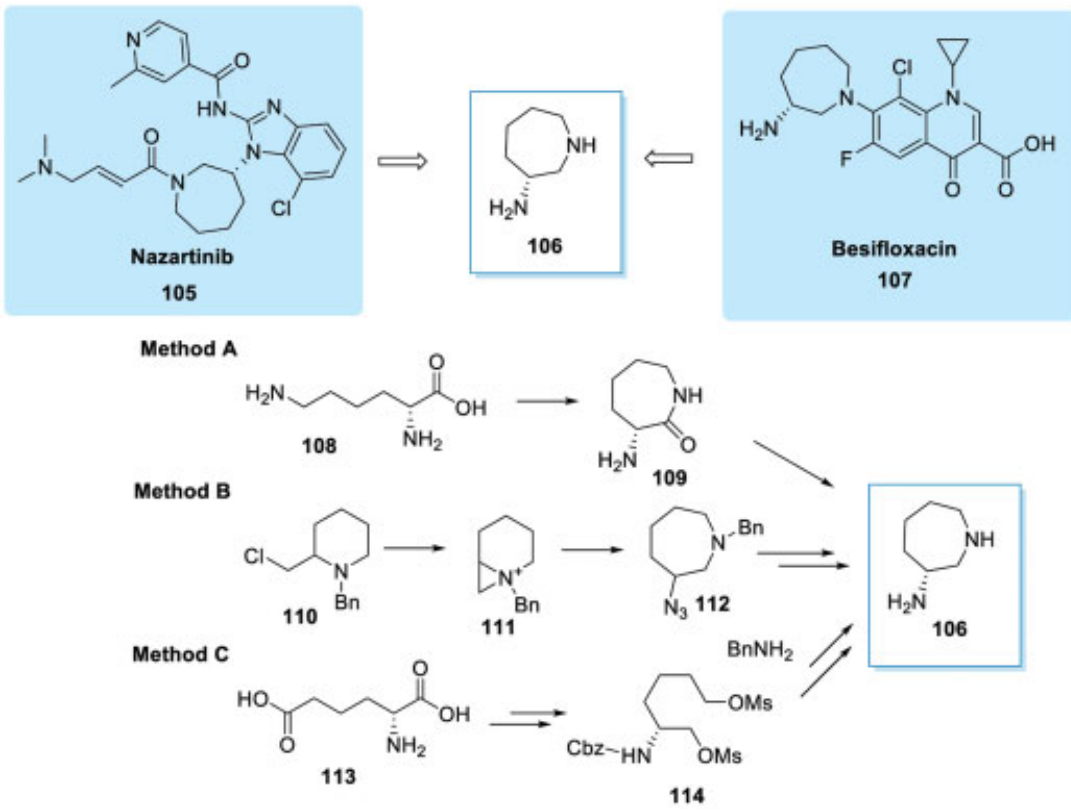

Scheme 24 Three known synthetic methods for (3R)-3-aminoazepane. 

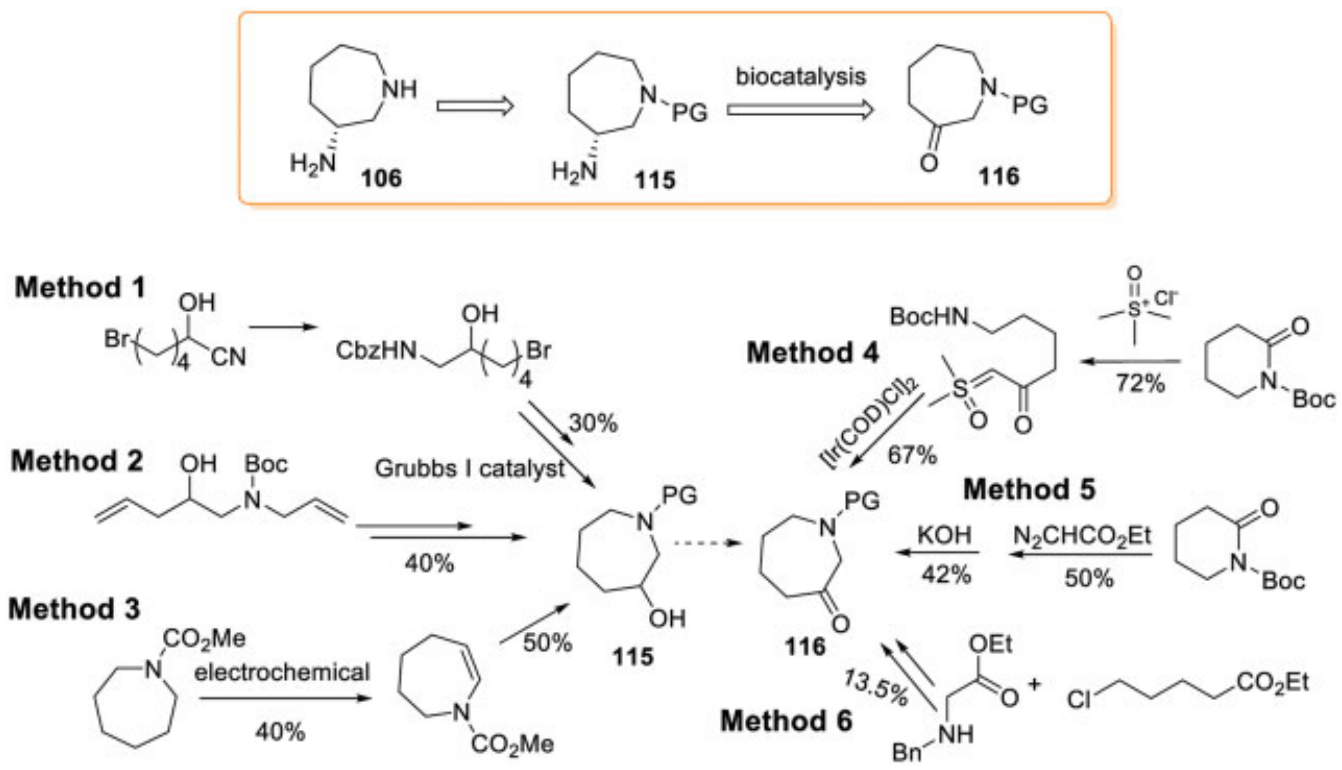

Scheme 25 The known catalytic transformation for 116.

used, and a large amount of isomer impurities (racemic) are generated, which are neither safe nor economical. The starting material of method $\mathrm{C}$ is expensive, which involves the reduction and protection of carboxylic acid and deprotection, and thus is not a good method in view of green chemistry principles.

Process chemists at HEC found that the above synthetic methods are not ideal, and a better method of preparing $\mathbf{1 0 6}$ is by enzyme or biocatalytic transformation. Although at least six synthetic routes are known, ${ }^{63}$ there are several disadvantages, among which are the high price of starting materials, the use of precious metal catalysts, unconventional chemical operation, and low overall yields (Scheme 25).

After careful consideration, HEC chemists finally developed a new route that uses commercially available piperidin2-one $\mathbf{1 1 7}$ as a starting material to access the target molecule effectively in seven steps (Scheme 26). (3R)-3-Aminoazepane
106 is prepared with $46.2 \%$ overall yield, $99.92 \%$ purity, and $99.2 \%$ ee. ${ }^{64}$ The practical enzymatic reaction catalyzed by transaminase is a key transformation. This new route avoids the use of expensive metal catalysts or chromatography. It is worth mentioning that the careful choice and optimization of the Dieckmann condensation reaction is a clever use of the telescoping process that avoids unnecessary separation and purification, while, at the same time, turning waste into treasure since a mixture of $\mathbf{1 2 1}$ and $\mathbf{1 2 2}$ gave only 123.

\section{P-Chiral Phosphorus Ligands and Enantioselective Synthesis of the Alkaloid (-)-Corynoline}

As the field of asymmetric catalysis rapidly progresses, the search for new, efficient, and practical asymmetric catalytic transformations to facilitate the green synthesis of chiral natural products and drugs will continue to be a major ongoing effort in organic chemistry. Chiral phosphorus<smiles>CCCCCCC(=O)OCCCCCNCC(=O)OCC</smiles>

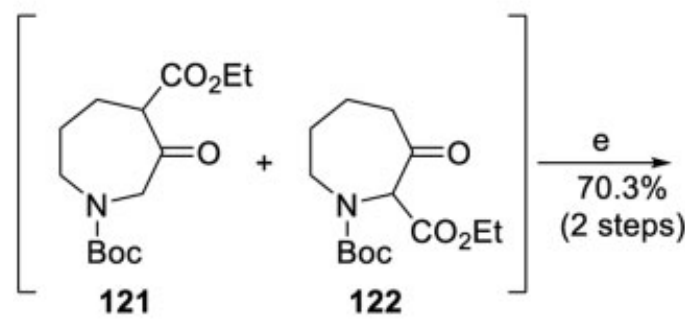<smiles>O=C1CCCCN([18OH])C1</smiles><smiles>CC(C)=CCC(C)NC(C)C</smiles><smiles>CC(C)(C)[NH+]1CCCCN(C(=O)c2ccccc2)C1</smiles><smiles>CC1CCCNC[C@H]1N(C)S(=O)(=O)[O-]</smiles>

total yield: $46.2 \%$, purity: $99.92 \%, 99.2 \%$ ee 


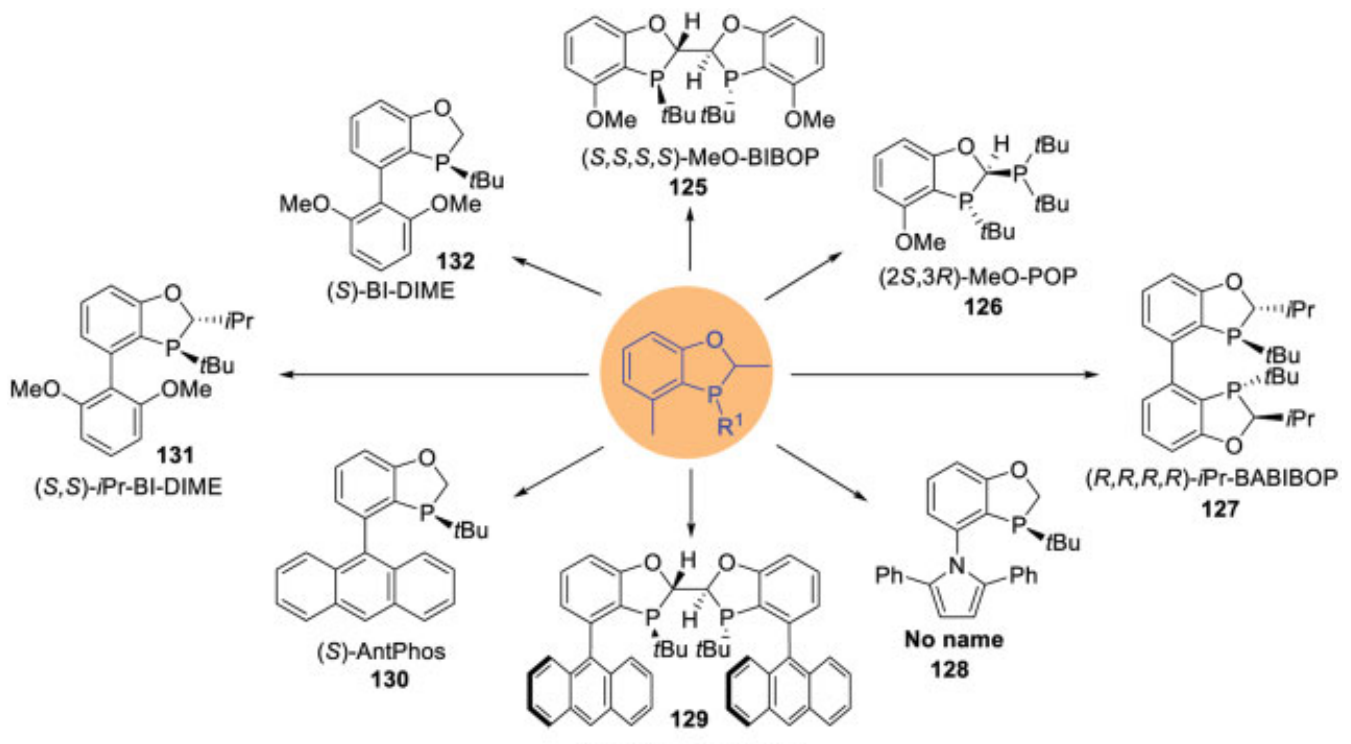

$(S, S, S, S)$-WingPhos

Scheme 27 Variety of P-chiral phosphorus ligands.

ligands have played a significant role in recent advances in transition-metal-catalyzed asymmetric transformations. However, there are numerous challenging issues of reactivity and selectivity in catalysis. The development of new and efficient chiral phosphorus ligands with new structural motifs remains highly desirable. P-Chiral phosphorus ligands have been overlooked and are under development as most Pchiral phosphorus ligands are either difficult to prepare or operationally inconvenient. The development of efficient, practical, and operationally convenient P-chiral phosphorus ligands with new structural motifs remains an important subject of research.

Tang and his team of SIOC developed a series of efficient and practical P-chiral bis- and mono-phosphorus ligands (Scheme 27). ${ }^{65}$ Their unique structural and physical properties include P-chirality, conformational clarity, high tunability of electronic and steric properties, and operational simplicity as air-stable solids, making them exceptional ligands for several asymmetric catalytic reactions. With their powerful P-chiral phosphorus ligands, in 2018, a concise, five-step synthesis of acetyl cholinesterase inhibitor (-)-corynoline 139 from known indanone was achieved (Scheme 28), ${ }^{66}$ in which the key step is an enantioselective palladium-catalyzed $\alpha$-arylation on the sterically hindered substrates. Next, radical dibromination at two benzylic positions gave dibromide, and treatment with methylamine then provided tertiary amine $\mathbf{1 3 7}$ in 37\% yield over two steps. A subsequent marvelous Büchner-CurtiusSchlotterbeck reaction successfully converted the sterically hindered indanone into (-)-corynolon 138 in 56\% yield.

Obviously, the construction of all-carbon quaternary centers is challenging due to the large steric effect, but it is also appealing. In particular, asymmetric catalytic methods

<smiles>Cc1c([C@]2(C)Cc3cc4c(cc3C2=O)OC(C)O4)ccc2c1OCO2</smiles><smiles>CN[SbH2](C)(C)[18OH]</smiles>

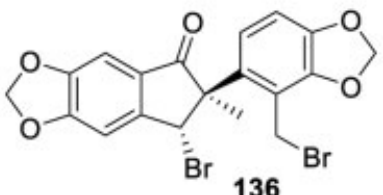

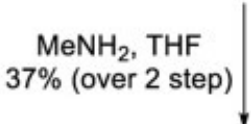<smiles>CN1Cc2c(ccc3c2OCO3)[C@@H]2[C@@H](O)Cc3cc4c(cc3[C@@H]21)OCO4</smiles>

(-)-corynoline 139<smiles>CN1Cc2c(ccc3c2OCO3)[C@@]2(C)C(=O)Cc3cc4c(cc3[C@H]12)OCO4</smiles>

138<smiles>CN1Cc2c(ccc3c2OCO3)[C@@]2(C)C(=O)c3cc4c(cc3[C@@H]12)OCO4</smiles>

Scheme 28 The five-step route of enantioselective synthesisof (-)-corynoline. 
<smiles>[R]c1ccc2c(c1)C(=O)C([R])C2</smiles>

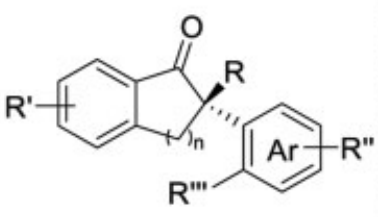

up to $98 \%$ yield up to $99 \%$ ee 142

Scheme $29 \mathrm{Pd}(\mathrm{OAc})_{2} / \mathrm{BI}$-DIME catalyzed asymmetric $\alpha$-arylation of sterically hindered substrates.

applicable to the synthesis of chiral natural products and pharmaceutical molecules containing all-carbon quaternary centers remain in high demand. Although there has been a great deal of synthetic effort, efficient asymmetric syntheses, particularly those based on asymmetric catalytic methods, are still lacking. In this case, the chiral all-carbon quaternary center was constructed with the assistance of the bulky P-chiral ligand BI-DIME, which was efficient for various cross-coupling reactions of sterically hindered substrates (Scheme 29). The method is practical and highly efficient, featuring excellent enantioselectivities and good functional group compatibility with up to $98 \%$ yield and $99 \%$ ee values. This reaction is expected to be extensively applicable in drug discovery and process chemistry. ${ }^{67}$

\section{Practical Asymmetric Synthesis of Chiral Cyclohexyl Spirobiindanes and Its Applications}

Transition-metal-catalyzed asymmetric reactions are a hot issue and at the frontier of current organic chemistry research. Many of these chiral spiro ligands and related catalysts have not only shown high catalytic activity and high enantioselectivity for various asymmetric reactions, but they have also made enantiocontrol of many catalytic asymmetric reactions, which are difficult in obtaining high enantioselectivities, easier and more feasible. Spiroketal-based diphosphine (SKP) ligands, developed by Ding's group at SOIC, turned out to be the most appropriate and versatile ligands (Scheme 30). ${ }^{68}$

The chiral spiro skeleton has become a "privileged structure," and chiral spiro ligands and catalysts have been used in the syntheses of different types of chiral compounds including chiral natural products and chiral drugs. ${ }^{69}$ For the synthesis of carbohydrates, which are polyhydroxylated compounds bearing multiple stereogenic centers, catalystdirected stereoselective carbonyl addition in the absence of protecting groups has only been achieved using enzymes. In 2016, direct anomeric propargylation of unprotected aldoses with excellent levels of catalyst-directed diastereoselectivity was achieved (Scheme 31). ${ }^{70}$ The key features of anomeric propargylation is the chirality of the catalyst derived from the SKP skeleton, not the internal stereogenic centers of substrates, which predominantly controls the stereochemistry of the propargylation step.

\section{Nickel Catalyst for Practical Asymmetric Hydrogenation of $\boldsymbol{N}$-Sulfonyl Imines}

Chiral amine compounds are important synthesis intermediates and have a wide range of applications in the synthesis of pharmaceuticals and fine chemicals. Asymmetric catalytic hydrogenation through imines is the most direct and efficient method of obtaining chiral amine compounds. ${ }^{71}$ In the past two decades, significant progress has been made in the asymmetric catalytic hydrogenation of imines. Various highly active, highly stereoselective chiral ligands and catalysts have been designed and synthesized, ${ }^{72}$ various new asymmetric catalytic methods and strategies have been developed and successfully applied, and important hydrogenation reactions of various special imine substrates have been important breakthroughs in pharmaceutical production. However, the asymmetric catalytic hydrogenation of $\mathrm{N}$-sulfonyl imine still has low reactivity, a narrow substrate range, and harsh reaction conditions. Catalysts for these reactions are precious metals such as $\mathrm{Rh}, \mathrm{Ru}, \mathrm{Ir}$, and $\mathrm{Pd}$ (compared with very cheap $\mathrm{Ni}$ ), on the other hand, chiral ligands are also expensive; therefore, the development of a more economical, highly efficient, highly selective, and


Scheme 30 Synthesis of chiral, aromatic spiroketals. 


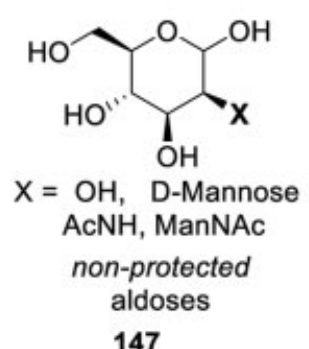

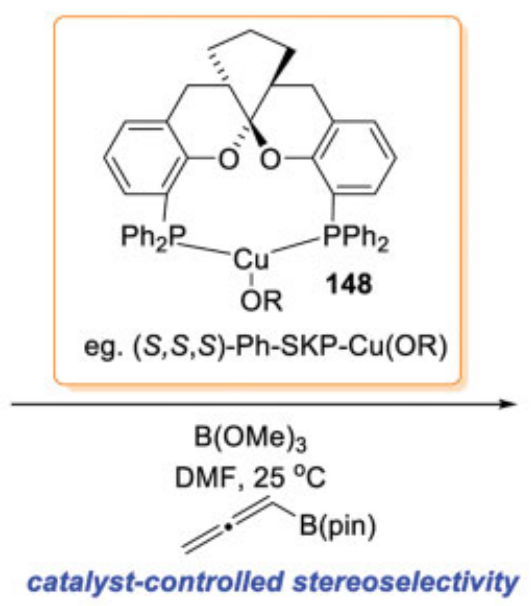

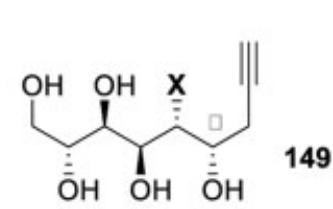

$95 \%$ Yield, $>20: 1 d r$ with $(S, S, S)$-Catalyst 3 steps<smiles>[Z][C@H]([C@@H](O)CC#C)[C@@H](O)[C@H](O)[C@H](O)CO</smiles>

$84 \%$ Yield, $>20: 1 d r$ with $(R, R, R)$-Catalyst<smiles>[Y]C1[C@@H]([C@H](O)[C@H](O)CO)O[C@](O)(C(=O)O)C[C@H]1O</smiles>

$\mathrm{X}=\mathrm{OH}, \mathrm{KDN}$ $\mathrm{AcNH}, \mathrm{Neu} 5 \mathrm{Ac}$<smiles>[X]C1[C@H](O)C[C@@](O)(C(=O)O)O[C@H]1[C@H](O)[C@H](O)CO</smiles>

Sialic Acid Derivatives

Scheme 31 Synthesis of sialic acids derivatives via (SKP-Cu)-catalyzed stereodivergent propargylation.

environmentally friendly asymmetric hydrogenation process or scale-up by the use of $\mathrm{Ni}$ is the future direction of asymmetric catalytic hydrogenation of imines.

Although hydrogenation reactions using chiral sulfenamides and $\mathrm{N}$-tert-butanesulfinyl imines has been reported occasionally for more than a decade, ${ }^{73}$ these reactions all use quantitative chiral sulfenamides as the starting material, such as $(R)$ or $(S)$-tert-butanesulfinamide, which are clearly not atom-economical. Furthermore, the catalyst is essentially a precious metal, such as Ru. The high loading of the catalyst indicates that it cannot comply with green-chemistry principles for sustainable development.

In 2001, it was reported that, in trifluoroethanol, fluorinated amino acids were prepared by Pd-catalyzed asymmetric hydrogenation of fluorinated iminoesters under the combined action of palladium and (R)-BINAP. ${ }^{74}$ In 2006, the palladium- and TangPhos-catalyzed hydrogenation of $\mathrm{N}$-tosylimines also made progress, ${ }^{75}$ but it is not ideal for broad applications and for scale-up in terms of the high loading of Pd, cost of the chiral ligands, and the limit of general applicability, attributed to the low turnover number.

Chiral sulfonamides are common pharmacophores and are considered to be useful isosteres of carboxylic acids and carboxamides in drug discovery. In 2018, Zhou and coworkers developed a stepwise reductive amination of aryl ketones and the corresponding tosylamines via nickel-catalyzed asymmetric transfer hydrogenation (Scheme 32). ${ }^{76}$ Formic acid was used as a safe and economical surrogate of high-pressure hydrogen gas. As a result, a drug candidate $\mathbf{1 5 8}$ for the treatment of type II diabetes was effectively prepared.

In 2019, a breakthrough in the first asymmetric catalytic hydrogenation of $\mathrm{N}$-sulfonyl imines catalyzed by an inexpensive metal, $\mathrm{Ni}$ (only $0.5 \mathrm{~mol} \%$ loading), with chiral ligand $(R, R)$ QuinoxP* was reported in Angewandte Chemie International Edition (Scheme 33). This paper was highlighted as a very important paper (VIP) and appeared as the cover story. ${ }^{77}$ The pioneering work performed by Zhang's group involved a practical and robust transformation that has many advantages,

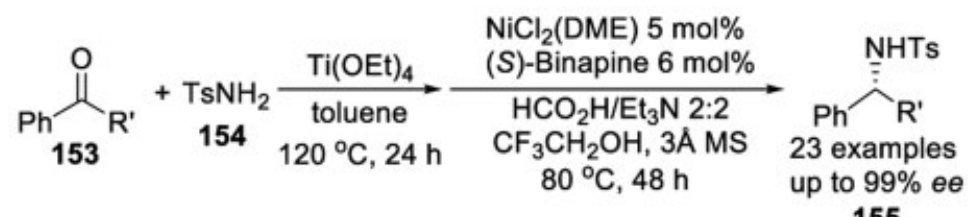

155
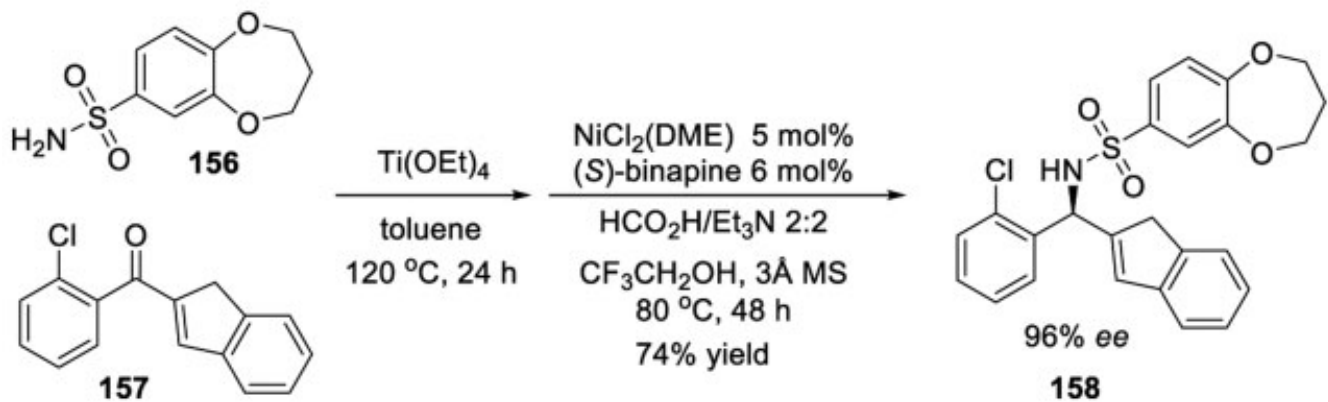

Scheme 32 Reductive amination of aryl ketones. 


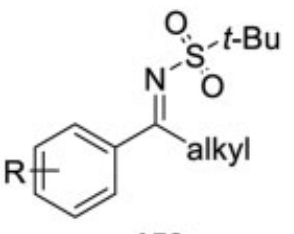

159
$\mathrm{Ni}(\mathrm{OAc})_{2} \cdot 4 \mathrm{H}_{2} \mathrm{O}(0.5 \mathrm{~mol} \%)$ $(R, R)$-QuinoxP* $(0.5 \mathrm{~mol} \%)$

$\mathrm{H}_{2}$ (30 bar), TFE, $50^{\circ} \mathrm{C} 24 \mathrm{~h}$

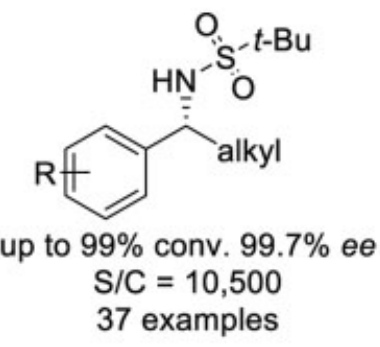

160

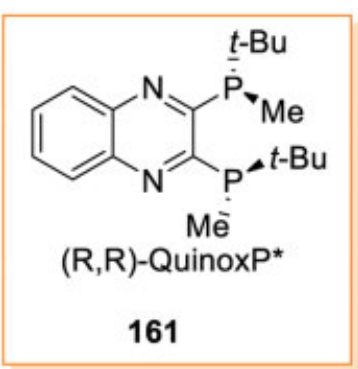

Scheme $33 \mathrm{Ni} /(R, R)$-QuinoxP*-catalyzed asymmetric catalytic hydrogenation of $\mathrm{N}$-sulfonyl imines.

including excellent enantioselectivities, high conversion rates, and amazingly high turnover numbers $(\mathrm{S} / \mathrm{C}=10,500$ so far when using $\mathrm{Ni})$, all while using minimal $(0.5 \mathrm{~mol} \%)$ and the cheapest nickel for asymmetric hydrogenation of prochiral $\mathrm{N}$ sulfonyl imines. We believe that this novel method will have wider application in the near future for pharmaceutical process development.

This excellent catalytic system is also suitable for three types of cyclic $\mathrm{N}$-sulfonyl imine substrates, including five- or six-membered cyclic benzosultams which are important bioactive molecules or drug candidates (Scheme 34 ).

It is worth noting that the ${ }^{t} \mathrm{Bu}$-sulfonyl groups could be easily removed by using $\mathrm{AlCl}_{3}$ to yield the corresponding chiral amines in excellent conversion without loss of ee (Scheme 35); nevertheless, we still hope a better deprotection method will be discovered in the future to make the entire process more eco-friendly.

\section{Revolutionary Process of HMG-CoA Reductase Inhibitors' Side Chain}

Statins, as HMG-CoA reductase inhibitors, are a class of very important drugs that regulate cholesterol biosynthesis, and which have led to reduced risk of atherosclerosis and cardiovascular disease. ${ }^{78}$ The pursuit of more potent statins uninterruptedly continued at the level of these natural and synthetic analogues, and, as a result of structural refinements, the third generation of synthetic statins-the so-called superstatinsrepresented by atorvastatin [-Fig. $\mathbf{7},(\mathbf{1 6 8})$ ], rosuvastatin
(169), fluvastatin(170), and pitavastatin(171)-was developed and launched on the market as more efficient hypolipidemic drugs. ${ }^{79}$ In particular, atorvastatin (168) was the first pharmaceutical product to reach annual sales of 10 billion dollars, and used to be the top-selling drug in the world. ${ }^{80}$ Structurally, these synthetic superstatins commonly possess a pivotal syn1,3-diol moiety with two stereogenic centers, which attaches to a heterocyclic core and poses an ongoing challenge for economical and eco-friendly synthesis toward statin targets. ${ }^{81}$

Obviously, central to the asymmetric synthesis of superstatins is the construction of the crucial chiral side chain. Continuous endeavors over more than 40 years have resulted in the development of numerous strategies for stereoselective generation of two stereocenters in the side chains of these statins. ${ }^{81}$ The industrial approaches have mostly centered on the manipulation of the chiral side chain $\mathbf{1 7 5}$ by well-established diastereoselective Narasaka-Prasad reduction of chiral $\beta$-hydroxy-3-ketoester 7 starting from readily available $L$-isoascorbic acid (172) or (S)-epichlorohydrin (173;Scheme 36). However, the major drawback of these large-scale syntheses liesin utilizing toxic cyanide as C1-synthon for lateral chain elongation. ${ }^{81,82}$

Chen and coworkers designed a recyclable dimerization of $(R, R)$-salen catalyst [FDU-06-12 catalyst (177)] to solve the problem of constructing a $\mathrm{C}-3$ stereocenter in the process of chemical kinetic resolution $(\mathbf{1 7 6} \rightarrow \mathbf{1 7 8})$ and also discovered the key technology of intramolecular diastereoselective oxidative bromocyclization $(\mathbf{1 7 9} \rightarrow \mathbf{1 8 0})$ for C-5 stereocenter<smiles>CC1=NS(=O)(=O)c2ccccc21</smiles>

162

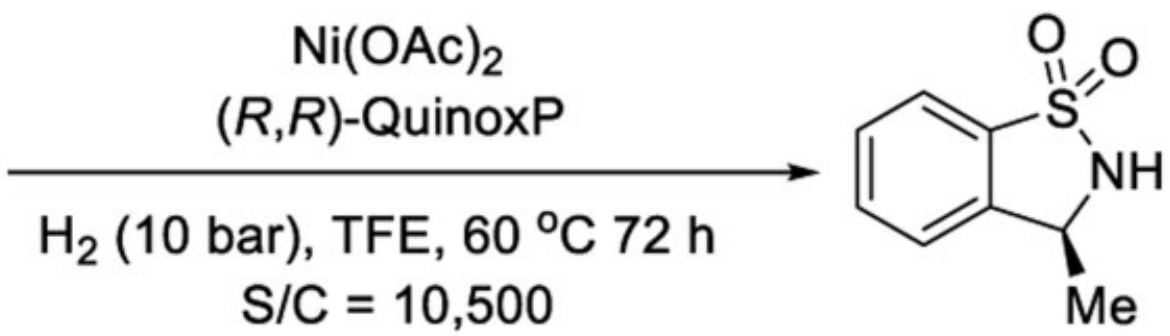

$99 \%$ yield, $93 \%$ ee

163

Scheme $34 \mathrm{Ni} /(R, R)$-QuinoxP*-catalyzed asymmetric catalytic hydrogenation of cyclic N-sulfonyl imine. 
<smiles>CC(NS(=O)C(C)(C)C)c1ccccc1</smiles>

$164,99 \%$ yield, $97 \%$ ee<smiles>COc1cccc([C@@H](C)NS(=O)(=O)C(C)(C)C)c1</smiles>

$166,97 \%$ yield, $93 \%$ ee<smiles>C[C@H](N)c1ccccc1</smiles>

$165,95 \%$ yield, $97 \%$ ee Anisole, $\mathrm{AlCl}_{3}$ $\mathrm{CH}_{2} \mathrm{Cl}_{2}, \mathrm{RT}, 2 \mathrm{~h}$.<smiles>COc1cccc([C@H](C)N)c1</smiles>

$167,93 \%$ yield, $93 \%$ ee

Scheme 35 Removal of chiral auxiliary t-Bu-sulfonyl group.

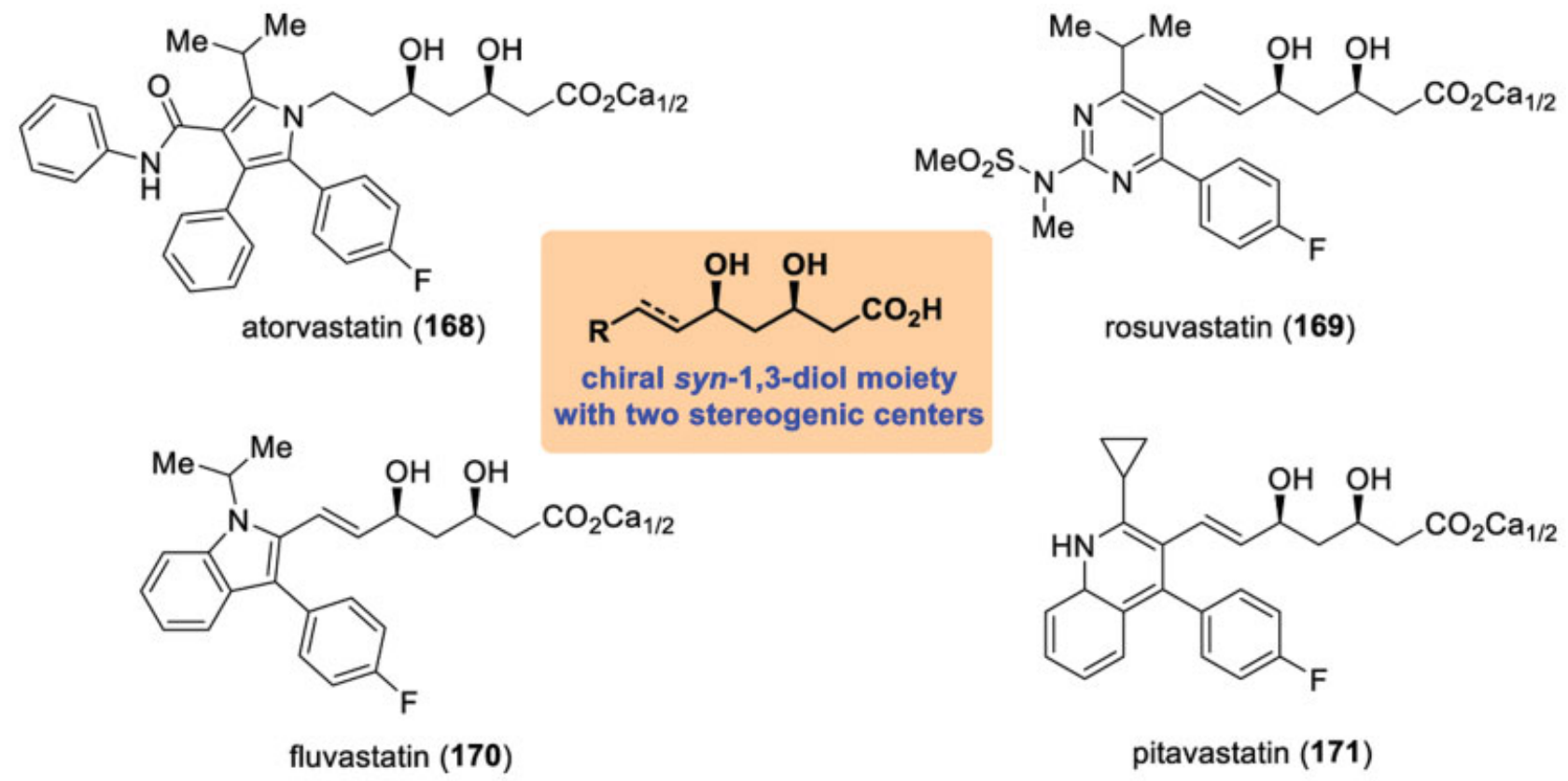

Fig. 7 Representative superstatins.

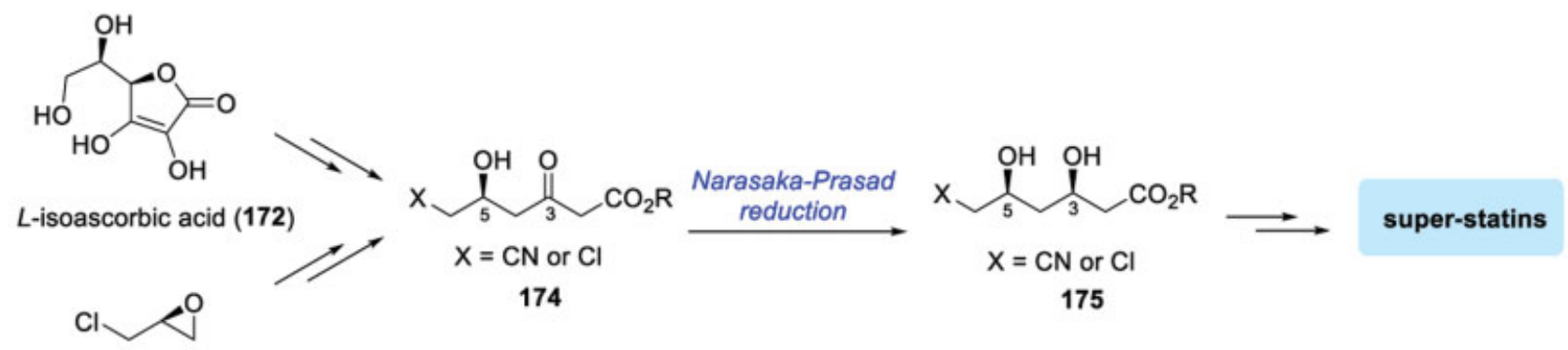

(S)-epichlorohydrin (173)

Scheme 36 Outline of the industrial process of superstatins. 

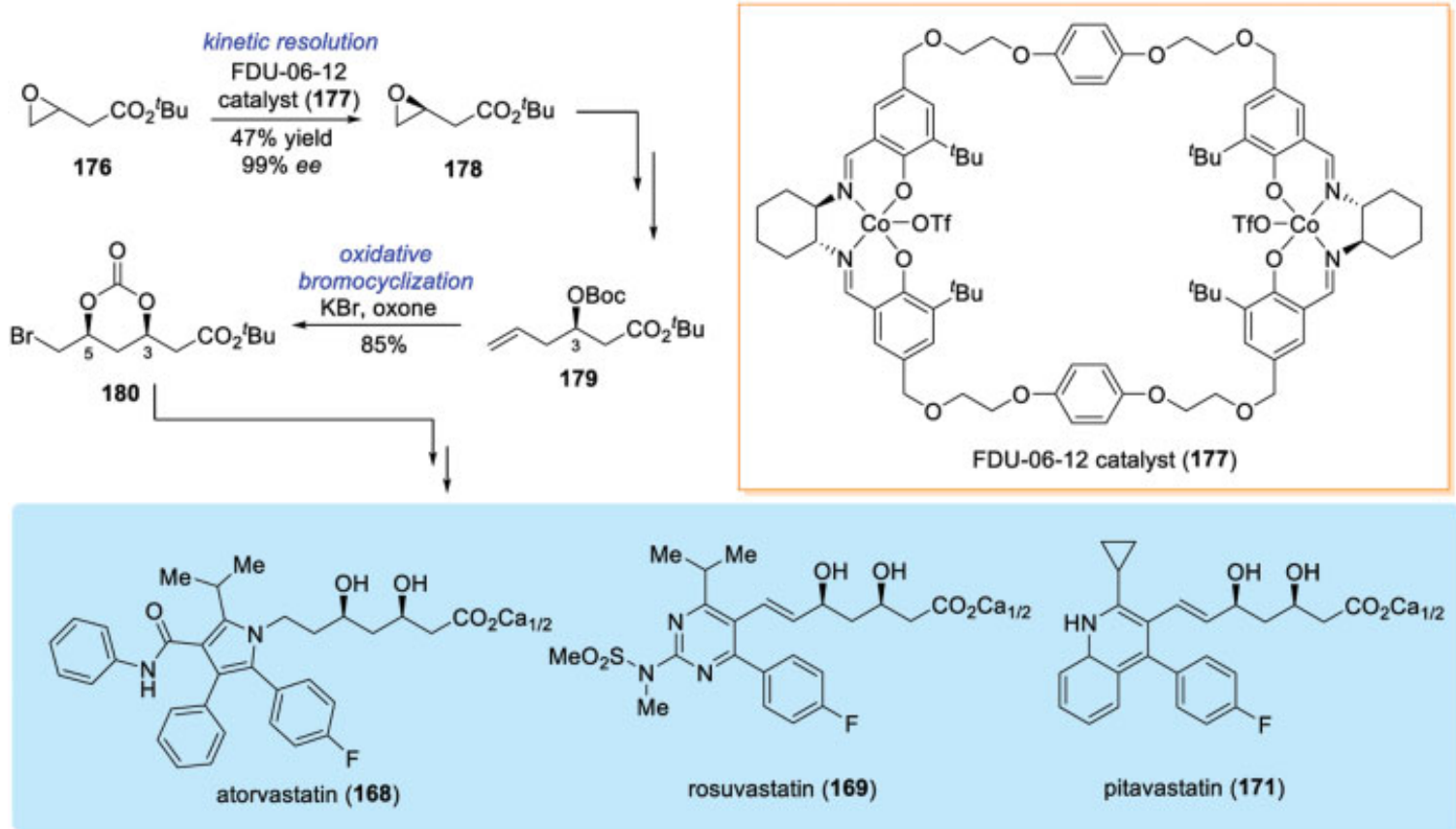

Scheme 37 Chen's resolution approach.

assembly (Scheme 37); in particular, this process could avoid the use of cyanide and greatly simplify the synthesis of the side chain and reduce costs. Then, Chen and coworkers achieved the efficient syntheses of atorvastatin (168), rosuvastatin (169), and pitavastatin (171). ${ }^{83}$

In 2014, Chen's group accomplished an efficient asymmetric synthesis of atorvastatin (168) through a novel approach that involved an organocatalytic enantioselective cyclic anhydride desymmetrization to establish C-3 stereogenicity and a cyanide-free assembly of the $\mathrm{C} 7$ amino-type side chain via a $\mathrm{C} 5+\mathrm{C} 2$ strategy as the key transformations. ${ }^{84}$ Employing their developed bifunctional sulfonamide catalyst (182) (Scheme 38), the enantioselective alcoholysis of $\mathbf{1 8 1}$ proceeded smoothly to deliver $\mathbf{1 8 3}$ in $93 \%$ yield and $90 \%$ ee. Subsequently, the cyanide-free installation of the $\mathrm{C} 7$ cyano-type side chain $\mathbf{1 8 4}$ occurred efficiently through a diethyl pyrocarbonate (DEPC)-promoted condensation of chiral hemiester $\mathbf{1 8 3}$ (C5 synthon) with methyl cyanoacetate (C2 synthon). The key C7 cyano-type side chain 184 was elaborated in several steps to amine $\mathbf{1 8 5}$, which could then be converted into atorvastatin (168) through a well-established sequence including a classical Paal-Knorr pyrrole approach.

Furthermore, Chen's group successfully developed a more streamlined approach to produce chiral syn-1,3-diol derivatives via asymmetric reduction strategies. ${ }^{86 a 85}$ Employing the $\mathrm{NaBH}_{4}-L$-tartaric acid system (Scheme 39), the prochiral ketone of readily available $\beta$-ketoester $\mathbf{1 8 6}$ can be reduced smoothly, to deliver the crucial enantioenriched homoallylic alcohols 187. This key transformation gives excellent control of the C-3 stereocenter (up to $86 \%$ yield, $>99 \%$ ee) and places<smiles>O=C1CC(O)CC(=O)O1</smiles>

181 catalytic asymmetric alcoholysis catalyst (182)

$\mathrm{MeOH}, 93 \%$ yield, $90 \%$ ee<smiles>COC(=O)CC(CCO)O[Ga]O</smiles>

183

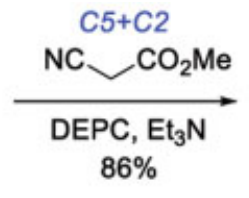

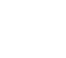<smiles>CC(=O)OCC(=O)CC(=O)C(=O)OCc1ccccc1</smiles>

184

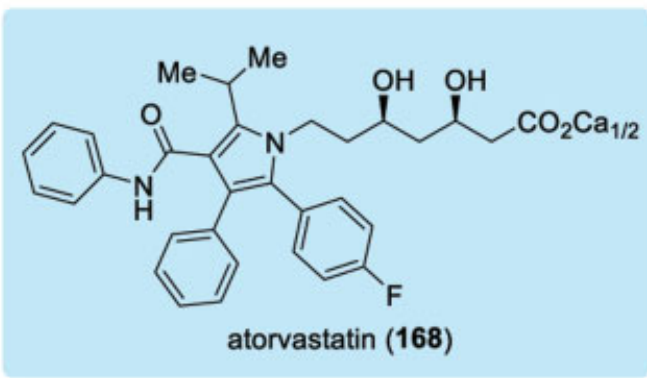<smiles>CC#CCNCC1CC(CC(=O)OC)OC(C)(C)O1</smiles>

Scheme 38 Chen's asymmetric alcoholysis approach. 


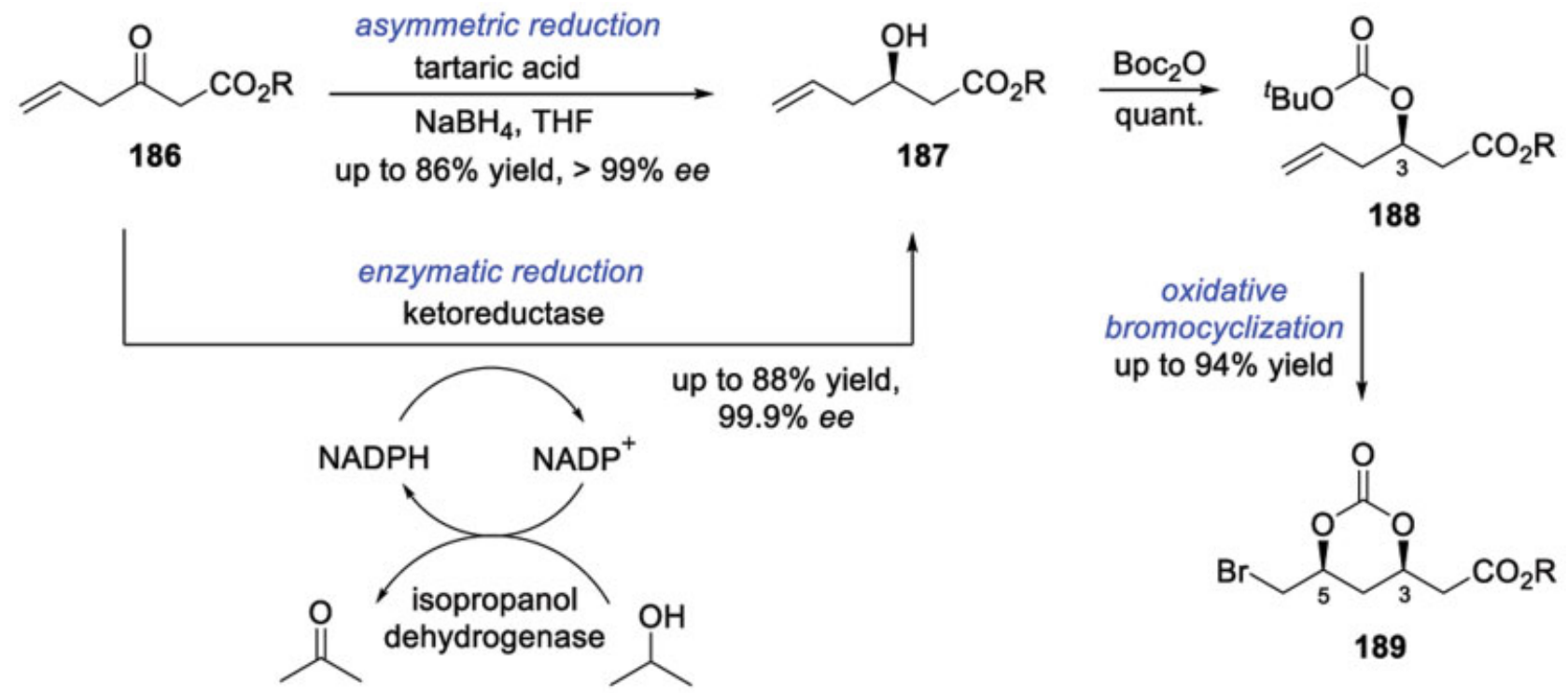

Scheme 39 Chen's chemical and enzymatic reduction-bromocyclization approach.

other necessary functional groups in the right position. The subsequent quantitative esterification with (Boc) ${ }_{2} \mathrm{O}$ led to ester 188, which was used in a diastereoselective oxidative bromocyclization protocol, affording syn-1,3-diol derivatives 189 in high yield (up to 94\%), which have been proved powerfully useful as intermediates in the total syntheses of superstatins. In addition, Chen and coworkers recently developed a novel enzymatic strategy for producing the pivotal chiral homoallylic alcohols $187 .^{87}$ As shown in Scheme 39, the biocatalytic approach involved the use of $\beta$-ketoester 186, which underwent bioreduction mediated by a ketoreductase (KRED) to afford the precursor of bromocyclization, homoallylic alcohols 187 in up to $88 \%$ yield with 99.9\% ee. An isopropanol dehydrogenase served as a cofactor recycling enzyme in this process. The aforementioned efficient chemical/enzymatic reduction-bromocyclization strategy would be greatly beneficial to the scalable synthesis of superstatins.

Most recently, in the continuous consideration of the synthesis of the syn-1,3-diol moiety, Chen's group developed a one-pot diastereo-controlled synthesis of chiral syn-1,3-diol derivatives via $\mathrm{CO}_{2}$ fixation/bromocyclization using in situgenerated ${ }^{t} \mathrm{BuOBr}$ in excellent yield and with both relative and absolute stereocontrol. ${ }^{86}$ As illustrated in Scheme 40, chiral homoallylic alcohol 190 was subjected to ${ }^{t} \mathrm{BuOCl}$ and $\mathrm{NaBr}$ under a continuously bubbling $\mathrm{CO}_{2}$ system to generate the crucial bromocarbonate product 180 in $76 \%$ yield with $>99 \%$ ee and $>19: 1 d r$. Subsequently, a well-known three-step sequence afforded the general intermediate kaneka alcohol 191, which could then be readily transformed to superstatins, such as atorvastatin (168), rosuvastatin (169), and pitavastatin (171). Notably, this methodology is the first example of using $\mathrm{CO}_{2}$ as

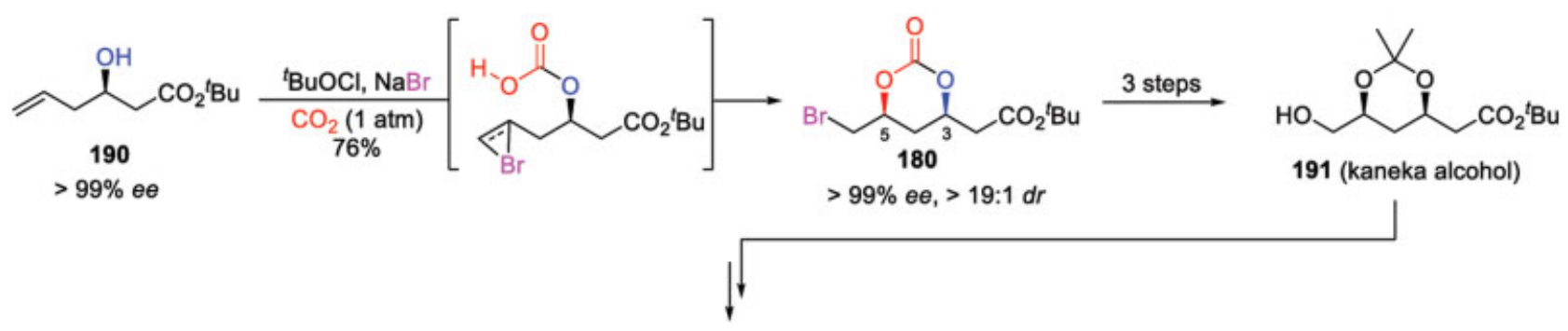<smiles>CC(C)c1c(C(=O)Nc2ccccc2)c(-c2ccccc2)c(-c2ccc(F)cc2)n1CCC(O)CC(O)CC(=O)OCC(C)(C)C</smiles><smiles>CC(C)c1nc(N(C)S(C)(=O)=O)nc(-c2ccc(F)cc2)c1/C=C/C(O)C[C@H](O)CC(=O)OC(C)(C)C</smiles><smiles>CC(C)(C)OC(=O)CC(O)C[C@@H](O)/C=C/C1=C(C2CC2)NC2C=CC=CC2=C1c1ccc(F)cc1</smiles>

Scheme 40 Chen's bromocarboxylation approach using $\mathrm{CO}_{2}$ as an oxygen source. 
an oxygen source to construct chiral syn-1,3-diol moieties, as well as the most ideal synthesis of the essential structures, with excellent environmental protection potential and huge commercial value. This procedure was patented and successfully applied in the asymmetric synthesis of statins on a pilot plant scale in a pharmaceutical company.

\section{Conclusions and Outlook}

Pharmaceutical process chemistry is a complex and multidisciplinary field. Better and greener pharmaceutical process chemistry has many characteristics such as (i) the ability to choose cheap and readily available starting materials in large supply; (ii) use of inexpensive reagents, catalysts, and solvents; (iii) establishment of a reliable, speedy, and robust process for producing high-quality intermediates and APIs; (iv) an economical and convenient production method; ( $v$ ) avoidance of high-risk operations and hazardous reagents; and (vi) use of safe and environmentally friendly operations and processes to reduce waste, including by-products, wastewater, and harmful gases. The above 12 case studies are representative of the outstanding achievements in developing greener pharmaceutical technologies and synthetic chemistries in the past two decades in China. In short, the green process has been a gradual and continuous development process, as there is no perfect process, but only a better process to innovate. Multiple improvements take time and contribute to the ultimate optimal process. The above cases show that the best comes later when one and more key transformations are greatly improved by using cutting-edge and eco-friendly synthetic methods and processes.

China has a strong chemical foundation and it is a major producer of APIs and thousands of pharmaceutical intermediates. However, compared with advanced European and American pharmaceutical giants, there is still a certain gap in the Chinese pharmaceutical industry, especially in process development, as there still needs to be vigorous advocacy for new environmentally friendly green technologies. In recent years, people's growing awareness of the importance of environmental protection has raised many challenges for China's pharmaceutical R\&D and production. Green pharmaceutical process is therefore an essential innovation for the healthy and sustainable development of the Chinese pharmaceutical industry. We also hope that Chinese chemists, whether in academia or in the industry, can better connect theory with empirical reality to tackle and truly solve the current challenges of pharmaceutical development and production for the betterment and protection of the environment and human health.

\section{Conflict of Interest}

The authors declare no conflicts of interest.

\section{Acknowledgments}

The authors are grateful for the support from the State Key Laboratory of Anti-Infective Drug Development (Sunshine Lake Pharma Co., Ltd; 2015DQ780357) and National Major Scientific and Technological Special Project for "Sig- nificant New Drugs Development" during the Thirteenth Five-year Plan Period(Grant No.2018ZX09201002-001). We are also grateful to Raymond Zhang at Cornell University for proofreading this manuscript.

\section{References}

1 Tan HL. China's pharmaceutical industry is poised for major growth. Available at: https://www.cnbc.com/2018/04/19/chinas-pharmaceutical-industry-is-poised-for-major-growth.html. Accessed April 19, 2018

2 Anastas PT, Warner JC. Green Chemistry: Theory and Practice. New York: Oxford Sciences Publications; 1998

3 Dunn PJ, Wells AS, Williams MT. Green Chemistry in the Pharmaceutical Industry. Weinheim: Wiley-VCH; 2010

4 (a) Cue BW,Zhang J. Green process chemistry in the pharmaceutical industry. Green Chem Lett Rev 2009;2(4):193-211. (b) Zhang J, Cue BW. Green process chemistry in the pharmaceutical industry: recent case studies. In: Zhang W, Cue BW, eds. Green Techniques for Organic Synthesis and Medicinal Chemistry. New Jersey: John Wiley \& Sons, Inc.; 2012: 631-658

5 Zhang W, Cue BW. Green Techniques for Organic Synthesis and Medicinal Chemistry. Weinheim: Wiley; 2018

6 Kogl F, Tonnis B, Hoppe-Seyl Z. Concerning bio-problems. representations of crystallized Biotin in egg yolk. 20. Communication concerning plant developments materials. Physiol Chem 1936;242:43

7 (a) De Clercq PJ. Biotin: a timeless challenge for total synthesis. Chem Rev 1997;97(6):1755-1792. (b) Seki M. Biological significance and development of practical synthesis of biotin. Med Res Rev 2006;26(4):434-482. (c) Eggersdorfer M, Laudert D, Létinois $\mathrm{U}$, et al. One hundred years of vitamins-a success story of the natural sciences. Angew Chem Int Ed Engl 2012;51(52):1296012990. (d) Zhong Z, Wu XF, Chen FE. Recent progresses in total synthesis of (+)-biotin. Youji Huaxue 2012;32:1792-1802 $10.6023 /$ cjoc1203041

8 Harris SA, Wolf DE, Mozingo R, Folkers K. Synthetic biotin. Science 1943;97(2524):447-448

9 (a) Sternbach LH. Chapter VI - Biotin. Compr Biochem 1963;11:6681. (b) Goldberg MW, Sternbach LH. Title is not available. US Pat. 2489232, Nov. 22, 1949 (Chem Abstr 1951;45:184). (c) Goldberg MW, Sternbach LH. Synthesis of biotin. US Pat. 2489235, Nov. 22, 1949 (Chem Abstr 1951;45:186a). (d) Goldberg MW, Sternbach LH. Debenzylation of benzylated imidazolido-thiophane compounds. US Pat. 2489238, Nov. 22, 1949 (Chem Abstr 1951;45:186g)

10 Gerecke M, Zimmermann JP, Aschwanden W. Biotin synthesis. Preparation of (3aS, 6aR)-1,3-dibenzyl-tetrahydro-4H-thieno(3,4d)imidazole-2,4(1H)-dione [in German]. Helv Chim Acta 1970;53 (05):991-999

11 Chen FE, Ling XH, Lu YX, et al. Studies on the asymmetry total synthesis of d-biotin (II). Chem J Chin Univ 2001;22(7):11411146

12 Matsuki K, Inoue H, Takeda M. Highly enantioselective reduction of meso-1,2-dicarboxylic anhydrides. Tetrahedron Lett 1993;34 (7): $1167-1170$

13 Chen FE, Huang YD, Fu H, et al. An efficient and enantioselective synthesis of d-biotin. Synthesis 2000;2000(14):2004-2008

14 Shimizu M, Nishigaki Y, Wakabayash A. Stereocontrol in the reduction of meso-imides using oxazaborolidine, leading to a facile synthesis of (+)-deoxybiotin. Tetrahedron Lett 1999;40 (50):8873-8876

15 (a) Chen FE, Dai HF, Kuang YY, et al. Synthetic studies on d-biotin. Part 7: A practical asymmetric total synthesis of d-biotin via enantioselective reduction of meso-cyclic imide catalyzed by oxazborolidine. Tetrahedron Asymmetry 2003;14(23):36673672. (b) Chen FE, Yuan JL, Dai HF, et al. Synthetic studies on dbiotin, part 6: an expeditious and enantiocontrolled approach to 
the total synthesis of d-biotin via a polymer-supported chiral oxazaborolidine-catalyzed reduction of meso-cyclic imide strategy. Synthesis 2003;2003(14):2155-2160. (c) Chen FE, Jia HQ, Chen XX, et al. Synthetic studies on d-biotin, part 9 . An improved asymmetric synthetic route to d-biotin via Hoffmann-Roche lactone-thiolactone approach. Chem Pharm Bull (Tokyo) 2005;53(7):743-746. (d) Chen FE. Process for the preparation of (3aS,4S,6aR)-1,3-dibenzyl-hexahydro- $1 H$-thieno[3,4-d]imidazol-2(3H)-one-4-pentanoic acid (dibenzylbiotin). Chem Abstr 2005; $143: 248383$

16 (a) Spivey AC, Andrews BI. Catalysis of the asymmetricdesymmetrization of cyclic anhydrides by nucleophilic ring-opening with alcohols. Angew Chem Int Ed 2001;40(17):3131-3134. (b) Chen Y, McDaid P, Deng L. Asymmetric alcoholysis of cyclic anhydrides. Chem Rev 2003;103(8):2965-2984.(c) Atodiresei I, Schiffers I, BolmC. Stereoselective anhydride openings. Chem Rev 2007;107(12):5683-5712

17 (a) Chen YG, Tian SK, Deng L. A highly enantioselective catalytic desymmetrization of cyclic anhydrides with modified cinchona alkaloids. J Am Chem Soc 2000;122(39):9542-9543. (b) Choi C, Tian SK, Deng L. A formal catalytic asymmetric synthesis of (+)-biotin with modified cinchona alkaloids. Synthesis 2001;2001(11):1737-1741

18 Rho HS, Oh SH, Lee JW, Lee JY, Chin J, Song CE. Bifunctional organocatalyst for methanolytic desymmetrization of cyclic anhydrides: increasing enantioselectivity by catalyst dilution. Chem Commun (Camb) 2008; (10):1208-1210 (b) Oh SH, Rho HS, Lee JW, et al. A highly reactive and enantioselective bifunctional organocatalyst for the methanolytic desymmetrization of cyclic anhydrides: prevention of catalyst aggregation. Angew Chem Int Ed Engl 2008;47(41):7872-7875

19 (a) Bolm C, Gerlach A, Dinter CL. Simple and highly enantioselective nonenzymatic ring opening of cyclic prochiral anhydrides. Synlett 1999;1999(2):195-196. (b) Bolm C, Schiffers I, Dinter CL, Gerlach A. Practical and highly enantioselective ring opening of cyclic meso-anhydrides mediated by cinchona alkaloids. J Org Chem 2000;65(21):6984-6991. (c) Bolm C, Schiffers I, Atodiresei I, Hackenberger CPR. An alkaloid-mediated desymmetrization of meso-anhydrides via a nucleophilic ring opening with benzyl alcohol and its application in the synthesis of highly enantiomerically enriched $\beta$-amino acids. Tetrahedron Asymmetry 2003;14 (22):3455-3467

20 Peschiulli A, Gun'ko Y, Connon SJ. Highly enantioselective desymmetrization of meso anhydrides by a bifunctional thiourea-based organocatalyst at low catalyst loadings and room temperature. J Org Chem 2008;73(6):2454-2457

21 (a) Huang J, Xiong F, Chen FE. Total synthesis of (+)-biotin via a quinine-mediated asymmetric alcoholysis of meso-cyclic anhydride strategy. Tetrahedron Asymmetry 2008;19(12):14361443. (b) Dai HF, Chen WX, Zhao L, et al. Synthetic studies on (+)-biotin, Part 11: application of cinchona alkaloid-mediated asymmetric alcoholysis of meso-cyclic anhydride in the total synthesis of (+)-biotin. Adv Synth Catal 2008;350(10):16351641. (c) Wang SX, Chen FE. A novel cost-effective thiourea bifunctional organocatalyst for highly enantioselective alcoholysis of meso-cyclic anhydrides: enhanced enantioselectivity by configuration inversion. Adv Synth Catal 2009;351(4):547-552. (d) Xiong F, Chen XX, Chen FE. An improved asymmetric total synthesis of $(+)$-biotin via the enantioselective desymmetrization of a meso-cyclic anhydride mediated by cinchona alkaloidbased sulfonamide. Tetrahedron Asymmetry 2010;21(6):665669. (e) Chen XX, Xiong F, Fu H, Liu ZQ Chen FE. Synthetic studies on (+)-biotin, part 15: A chiral squaramide-mediated enantioselective alcoholysis approach toward the total synthesis of (+)-biotin. Chem Pharm Bull (Tokyo) 2011;59(4):488-491. (f) Xiong F, Xiong FJ, Chen WX, et al. Highly enantioselective methanolysis of meso-cyclic anhydride mediated by bifunctional thiourea cinchona alkaloid derivatives: access to asymmetric total synthesis of (+)-biotin. J Heterocycl Chem 2013;50(5):1078-1082. (g) Wang H, Yan L, Wu Y, Lu Y, Chen F. Asymmetric synthesis of vitamin D3 analogues: organocatalytic desymmetrization approach toward the A-ring precursor of calcifediol. Org Lett 2015;17(21):54525455

22 Chen FE. Synthesis of d-biotin. CN Pat. 1374312, Oct. 16, 2002 (Chem Abstr 2003;140:181254)

23 Shioiri T, Izawa K, Konoike T. Pharmaceutical Process Chemistry. Weinheim: Wiley-VCH; 2011

24 Xiao YC, Chen FE. Chloramphenicol base in asymmetric synthesis. ChemCatChem 2019;11:2043

25 (a) Wang X, Xu L, Xiong F, et al. A new cost-effective Ru-chloramphenicol base derivative catalyst for the asymmetric transfer hydrogenation/dynamic kinetic resolution of N-Boc alpha-aminobeta-ketoesters and its application to the synthesis of the chiral core of vancomycin. RSC Advances 2016;6(44):37701-37709. (b) Wang $\mathrm{X}, \mathrm{Xu} \mathrm{L}$, Yan L, et al. Catalytic asymmetric transfer hydrogenation/ dynamic kinetic resolution: an efficient synthesis of florfenicol. Tetrahedron 2016;72(14):1787-1793. (c) Wang H, Yan L, Xiong F, et al. New chloramphenicol Schiff base ligands for the titaniummediated asymmetric aldol reaction of alpha,beta-unsaturated aldehydes with diketene: a short synthesis of atorvastatin calcium. RSC Advances 2016;6(79):75470-75477. (d) Yan L, Wang HF, Chen WX, et al. Development of bifunctional thiourea organocatalysts derived from a chloramphenicol base Scaffold and their use in the enantioselective alcoholysis of meso cyclic anhydrides. ChemCatChem 2016;8(13):2249-2253. (e) Yan L, Wang H, Xiong F, et al. Chloramphenicol base chemistry. Part 11: Chloramphenicol base-derived thiourea-catalyzed enantioselective Michael addition of malononitrile to $\alpha, \beta$-unsaturated ketones. Tetrahedron Asymmetry 2017;28(7):921-929. (f) Wang H, Yan L, Wu Y, et al. Chloramphenicol base chemistry. Part 10(1): Asymmetric synthesis of alpha-hydroxy chiral alcohols via intramolecular Michael additions of gamma-hydroxy-alpha,beta-unsaturated enones with chloramphenicol base derived bifunctional urea organocatalysts. Tetrahedron 2017;73(19):2793-2800. (g) Yang HJ, Xiong FJ, Li J, et al. A family of novel bifunctional organocatalysts: Highly enantioselective alcoholysis of meso cyclic anhydrides and its application for synthesis of the key intermediate of P2X(7) receptor antagonists. Chin Chem Lett 2013;24(7):553-558. (h) Xu L, Han S, Yan L, Wang H, Peng $\mathrm{H}$, Chen F. Novel amide-functionalized chloramphenicol base bifunctional organocatalysts for enantioselective alcoholysis of meso-cyclic anhydrides. Beilstein J Org Chem 2018;14:309-317. (i) Yang HJ, Xiong FJ, Chen XF, et al. Highly enantioselective thiolysis of prochiral cyclic anhydrides catalyzed by amino alcohol bifunctional organocatalysts and its application to the synthesis of pregabalin. Eur J Org Chem 2013;2013(21):4495-4498. (j) Wang Y, Huang G, Hu S, et al. Enantioselective beta-hydroxy thioesters formation via decarboxylative aldol reactions of malonic acid half thioesters with aldehydes promoted by chloramphenicol derived sulfonamides. Tetrahedron 2017;73(34):5055-5062. (k) Yan L, Huang G, Wang $\mathrm{H}$, et al. Squaramide-linked chloramphenicol base hybrid catalysts for the asymmetric Michael addition of 2,3dihydrobenzofuran-2-carboxylates to nitroolefins. Eur J Org Chem 2017;2018(1):99-103

26 World Health Organization. World Malaria Report 2018. Available at: https://www.who.int/malaria/publications/world-malaria-report-2018/en/. Accessed November 19, 2018

27 Eastman RT, Fidock DA. Artemisinin-based combination therapies: a vital tool in efforts to eliminate malaria. Nat Rev Microbiol 2009;7(12):864-874

28 Paddon CJ, Westfall PJ, Pitera DJ, et al. High-level semi-synthetic production of the potent antimalarial artemisinin. Nature 2013; 496(7446):528-532

29 Liu DL, Zhang WB. The development on the research of industrial production of artemisinin. Chin Sci Bull 2017;62(18):1997-2006

30 Hao HD, Li Y, Han WB, Wu Y. A hydrogen peroxide based access to qinghaosu (artemisinin). Org Lett 2011;13(16):4212-4215 
31 Zhang W, Liu D, Yuan Q. Method for preparing artemisinin by artemisinic acid. Publication Number. WO Pat. 2013181913, Dec. 12,2013

32 Li J, Shen J, Xia C, Wang Y, Liu D, Zhang W. Asymmetric hydrogenation of $\alpha$-substituted acrylic acids catalyzed by a ruthenocenyl phosphino-oxazoline-ruthenium complex. Org Lett 2016; 18(09):2122-2125

33 (a) ElSohly HN, Croom EM, El-Feraly FS, et al. A large-scale extraction technique of artemisinin from Artemisia annua. J Nat Prod 1990;53(6):1560-1564. (b) Covello PS. Making artemisinin. Phytochemistry 2008;69(17):2881-2885

34 D'Incalci M, Galmarini CM. A review of trabectedin (ET-743): a unique mechanism of action. Mol Cancer Ther 2010;9(08): 2157-2163

35 Cuevas C, Francesch A. Development of Yondelis (trabectedin, ET743). A semisynthetic process solves the supply problem. Nat Prod Rep 2009;26(03):322-337

36 Zheng X, Schwarz K, Furuuchi T, et al. Making V(D)J rearrangement visible: quantification of recombination efficiency in real time at the single cell level. J Immunol Methods 2006;315(1-2): 133-143

37 Kawagishi F, Toma T, Inui T, Yokoshima S, Fukuyama T. Total synthesis of ecteinascidin 743. J Am Chem Soc 2013;135(37): 13684-13687

38 Corey EJ, Gin DY, Kania RS. Enantioselective total synthesis of ecteinascidin 743. J Am Chem Soc 1996;118(38):9202-9203

39 Chen J, Chen X, Bois-Choussy M, Zhu J. Total synthesis of ecteinascidin 743. J Am Chem Soc 2006;128(1):87-89

40 He W, Zhang Z, Ma D. A scalable total synthesis of the antitumor agents Et-743 and lurbinectedin. Angew Chem Int Ed Engl 2019;58(12):3972-3975

41 (a) Ma D, Zhang Y, Yao J, et al. Accelerating effect induced by the structure of $\alpha$-amino acid in the Copper-catalyzed coupling reaction of aryl halides with $\alpha$-amino acids: Synthesis of benzolactamV8. J Am Chem Soc 1998;120(48):12459-12467. (b) Ma D, Cai Q Zhang $\mathrm{H}$. Mild method for Ullmann coupling reaction of amines and aryl halides. Org Lett 2003;5(14):2453-2455. (c) Pan X, Cai Q Ma D. CuI/N,N-dimethylglycine-catalyzed coupling of vinyl halides with amides or carbamates. Org Lett 2004;6(11):1809-1812

42 (a) Bhunia S, Pawar GG, Kumar SV, et al. Selected copper-based reactions for $\mathrm{C}-\mathrm{N}, \mathrm{C}-\mathrm{O}, \mathrm{C}-\mathrm{S}$, and $\mathrm{C}-\mathrm{C}$ bond formation. Angew Chem Int Ed 2017;56(51):16136-16179. (b) Ma D, Cai Q. Copper/ amino acid catalyzed cross-couplings of aryl and vinyl halides with nucleophiles. Acc Chem Res 2008;41(11):1450-1460

43 De Lange B, Hyett DJ, Maas PJ, et al. Asymmetric synthesis of (S)-2indolinecarboxylic acid by combining biocatalysis and homogeneous catalysis. ChemCatChem 2011;3(2):289-292

44 Zhao J, Niu S, Jiang X, et al. A class of amide ligands enable $\mathrm{Cu}-$ catalyzed coupling of (hetero)aryl halides with sulfinic acid salts under mild conditions. J Org Chem 2018;83(12):6589-6598

45 Enache LA, Kennedy I, Sullins DW, et al. Development of a scalable synthetic process for DG-051B, a First-in-Class inhibitior of LTA4H. Org Process Res Dev 2009;13(6):1177-1184

46 Ribecai A, Bacchi S, Delpogetto M, et al. Identification of a manufacturing route of novel CRF-1 antagonists containing a 2,3-dihydro-1H-pyrrolo[2,3-b]pyridine moiety. Org Process Res Dev 2010;14(4):895-901

47 Ma D, Niu S, Zhao J, et al. A new class of amide ligands enable Cucatalyzed coupling of sodium methanesulfinate with (hetero)aryl chlorides. Chin J Chem 2017;35(11):1661-1664

48 Fan M, Zhou W, Jiang Y, Ma D. CuI/oxalamide catalyzed couplings of (hetero)aryl chlorides and phenols for diaryl ether formation. Angew Chem Int Ed Engl 2016;55(21):6211-6215

49 DiRocco DA, Ji Y, Sherer EC, et al. A multifunctional catalyst that stereoselectively assembles prodrugs. Science 2017;356(6336):426430

50 Liu S, Zhang ZF, Xie F, et al. First catalytic enantioselective synthesis of P-stereogenic phosphoramides via kinetic resolution promoted by a chiral bicyclic imidazole nucleophilic catalyst. Tetrahedron Asymmetry 2012;23(5):329-332

51 Zhang ZF, Wang M, Xie F, et al. Chiral bicyclic imidazole nucleophilic catalysts: design, synthesis, and application to the kinetic resolution of arylalkylcarbinols. Adv Synth Catal 2014;356(1415):3164-3170

52 (a) Zhang Z, Xie F, Jia J, Zhang W. Chiral bicycle imidazole nucleophilic catalysts: rational design, facile synthesis, and successful application in asymmetric Steglich rearrangement. J Am Chem Soc 2010;132(45):15939-15941. (b) Wang M, Zhang Z, Liu $\mathrm{S}$, Xie F, Zhang W. Enantioselective Black rearrangement catalyzed by chiral bicyclic imidazole. Chem Commun (Camb) 2014;50 (10):1227-1230

53 Xie JH, Zhou QL. New progress and prospects of transition metalcatalyzed asymmetric hydrogenation. Acta Chimi Sin 2012;70 (13):1427-1438

54 Liu G, Liu X, Cai Z, Jiao G, Xu G, Tang W. Design of phosphorus ligands with deep chiral pockets: practical synthesis of chiral $\beta$ arylamines by asymmetric hydrogenation. Angew Chem Int Ed Engl 2013;52(15):4235-4238

55 Ge Y, Han Z, Wang Z, Ding K. Ir-catalyzed double asymmetric hydrogenation of 3,6-dialkylidene-2,5-diketopiperazines for enantioselective synthesis of cyclic dipeptides. J Am Chem Soc 2019;141(22):8981-8988

56 Ojima I. Catalytic Asymmetric Synthesis. 3rd ed. New Jersey: John Wiley \& Sons, Inc.; 2010

57 (a) Hu AG, Fu Y, Xie JH, et al. Monodentate chiral spiro phosphoramidites: efficient ligands for Rhodium-catalyzed enantioselective hydrogenation of enamides. Angew Chem Int Ed 2002;41 (13):2348-2350. (b) Liu B, Zhu SF, Zhang W, Chen C, Zhou QL. Highly enantioselective insertion of carbenoids into N-H bonds catalyzed by copper complexes of chiral spiro bisoxazolines. J Am Chem Soc 2007;129(18):5834-5835

58 Yan PC, Zhang XY, Hu XW, et al. First asymmetric synthesis of Silodosin through catalytic hydrogenation by using Ir-SIPHOX catalysts. Tetrahedron Lett 2013;54(11):1449-1451

59 Liu D, Gao W, Wang C, Zhang X. Practical synthesis of enantiopure $\gamma$-amino alcohols by rhodium-catalyzed asymmetric hydrogenation of $\beta$-secondary-amino ketones. Angew Chem Int Ed Engl 2005;44(11):1687-1689 (b) Gao M, Meng JJ, Lv H, Zhang X. Highly regio- and enantioselective synthesis of $\gamma, \delta$-unsaturated amido esters by catalytic hydrogenation of conjugated enamides. Angew Chem Int Ed Engl 2015;54(6):1885-1887

60 Ahmad S, Sutherland A. Stereoselective synthesis of hydroxylated 3-aminoazepanes using a multi-bond forming, three-step tandem process. Org Biomol Chem 2012;10(41):8251-8259

61 Yang ZZ, Zhang L, Jiao HR, et al. A concise and highly efficient synthesis of praziquantel as an anthelmintic drug. Heterocycles 2016;92(11):1983-1993

62 (a) Botteghi C, Schionato A. Asymmetrische katalysen: XLVI. Enantioselektive Hydrosilylierung von Ketonen mit [Rh(COD)Cl] 2 und optisch aktiven Stickstoff-Liganden. J Organomet Chem 1989;370(1-3):17-31. (b) Chong HS, Garmestani K, Bryant LH Jr, Brechbiel MW. Synthesis of DTPA analogues derived from piperidine and azepane: potential contrast enhancement agents for magnetic resonance imaging. J Org Chem 2001;66(23):77457750. (c) Harit VK, Ramesh NG. A chiron approach to diversityoriented synthesis of aminocyclitols, (-)-conduramine F-4 and polyhydroxyaminoazepanes from a common precursor. J Org Chem 2016;81(23):11574-11586

63 (a) Monterde MI, Nazabadioko S, Rebolledo F, et al. Chemoenzymatic synthesis of azacycloalkan-3-ols. Tetrahedron: Asymmetry 1999;10(17):3449-3455. (d) Kono M, Harada S, Hamada Y, et al. Formal amide insertion strategy for the synthesis of anatoxin-a using rhodium catalysis. Tetrahedron 2016;72(10):1395-1399

64 (a) Feng Y, Luo Z, Sun G, et al. Development of an efficient and scalable biocatalytic route to (3R)-3-aminoazepane: a pharmaceutically important intermediate. Org Process Res Dev 2017;21 
(4):648-654. (b) Feng Y, Wang Z, Luo Z, et al. Further optimization of a scalable biocatalytic route to (3R)-N-Boc-3-aminoazepane with immobilized $\omega$-transaminase. Org Process Res Dev 2019;23 (3):355-360

$65 \mathrm{Xu} \mathrm{G}$, Senanayake $\mathrm{CH}$, Tang W. P-Chiral phosphorus ligands based on a 2,3-dihydrobenzo[ d][1,3]oxaphosphole motif for asymmetric catalysis. Acc Chem Res 2019;52(04):1101-1112

66 Rao X, Li N, Bai H, Dai C, Wang Z, Tang W. Efficient synthesis of (-)-corynoline by enantioselective palladium-catalyzed $\alpha$-arylation with sterically hindered substrates. Angew Chem Int Ed Engl 2018;57(38):12328-12332

$67 \mathrm{Fu} \mathrm{W}$, Tang W. Chiral monophosphorus ligands for asymmetric catalytic reactions. ACS Catal 2016;6(8):4814-4858

68 Wang X, Han Z, Wang Z, Ding K. Catalytic asymmetric synthesis of aromatic spiroketals by spinphox/iridium(I)-catalyzed hydrogenation and spiroketalization of $\alpha, \alpha^{\prime}$-bis(2-hydroxyarylidene) ketones. Angew Chem Int Ed Engl 2012;51(4):936-940

69 Zheng Z, Cao Y, Chong Q et al. Chiral cyclohexyl-fused spirobiindanes: practical synthesis, ligand development, and asymmetric catalysis. J Am Chem Soc 2018;140(32):10374-10381

70 Wei XF, Shimizu Y, Kanai M. An expeditious synthesis of sialic acid derivatives by copper(I)-catalyzed stereodivergent propargylation of unprotected aldoses. ACS Cent Sci 2016;2(01):21-26

71 Kobayashi S, Ishitani H. Catalytic enantioselective addition to imines. Chem Rev 1999;99(05):1069-1094

72 Tang W, Zhang X. New chiral phosphorus ligands for enantioselective hydrogenation. Chem Rev 2003;103(08):3029-3070

73 (a) Colyer JT, Andersen NG, Tedrow JS, Soukup TS, Faul MM. Reversal of diastereofacial selectivity in hydride reductions of Ntert-butanesulfinyl imines. J Org Chem 2006;71(18):6859-6862. (b) Guijarro D, Pablo O, Yus M. Asymmetric synthesis of chiral primary amines by transfer hydrogenation of $\mathrm{N}$-(tert-butanesulfinyl)ketimines. J Org Chem 2010;75(15):5265-5270. (c) Xiao X, Wang H, Huang Z, Yang J, Bian X, Qin Y. Selective diethylzinc reduction of imines in the presence of ketones catalyzed by $\mathrm{Ni}$ (acac) 2 . Org Lett 2006;8(1):139-142

74 Abe H, Amii H, Uneyama K. Pd-catalyzed asymmetric hydrogenation of alpha-fluorinated iminoesters in fluorinated alcohol: a new and catalytic enantioselective synthesis of fluoro alphaamino acid derivatives. Org Lett 2001;3(03):313-315

75 Yang Q, Shang G, Gao W, Deng J, Zhang X. A highly enantioselective, Pd-TangPhos-catalyzed hydrogenation of $\mathrm{N}$-tosylimines. Angew Chem Int Ed Engl 2006;45(23):3832-3835

76 Zhao X, Xu H, Huang X, Zhou JS. Asymmetric stepwise reductive amination of sulfonamides, sulfamates, and a phosphinamide by nickel catalysis. Angew Chem Int Ed Engl 2019;58(1):292-296

77 Li B, Chen J, Zhang Z, Gridnev ID, Zhang W. Nickel-catalyzed asymmetric hydrogenation of $\mathrm{N}$-sulfonyl imines. Angew Chem Int Ed Engl 2019;58(22):7329-7334

78 (a) Endo A, Kuroda M, Tsujita YJ. ML-236A, ML-236B, and ML236C, new inhibitors of cholesterogenesis produced by penicilium citrinum. Antibotics 1976;29(12):1346-1348. (b) Gaw A, Packard CJ, Shepherd J. Statins: The HMG-CoA Reductase Inhibitors in Perspective, 2nd ed. London: CRC Press; 2004.(c) Tobert JA. Lovastatin and beyond: the history of the HMG-CoA reductase inhibitors. Nat Rev Drug Discov 2003;2(7):517-526

79 (a) Li JJ, Johnson DS, Sliskovic DR, Roth BD, Eds. Contemporary Drug Synthesis. New-Jersey: Wiley-Interscience; 2004. (b) Johnson DS, Li JJ. The Art of Drug Synthesis. New York:Wiley;2007. (c) C̆asar Z. Recent progress in the synthesis of super-statins. SynthHeterocycl Contemporary MedChem 2016;44:113-185. (d) Chen Y, Chen C, Wu X. Dicarbonyl reduction by single enzyme for the preparation of chiral diols. Chem Soc Rev 2012;41 (5):1742-1753

80 Patel JM. Biocatalytic synthesis of atorvastatin intermediates. J Mol Catal, B Enzym 2009;61(3-4):123-128

81 (a) Miyachi N, Suzuki M, Ohara Y, et al. Syntheses of HMG-CoA reductase inhibitors. Synth Org Chem Jpn 1995;53(3):186-196. (b) Časar Z. Historic overview and recent advances in the synthesis of super-statins. Curr Org Chem 2010;14(8):816-845. (c) Andrushko N, Andrushko V, Tararov V, Korostylev A, König G, Börner A. Highly stereoselective hydrogenations-as key-steps in the total synthesis of statins. Chirality 2010;22(5):534-541. (d) WuY. Xiong FJ, Chen FE. Stereoselective synthesis of 3-hydroxy-3-methylglutaryl-coenzyme A reductase inhibitors. Tetrahedron 2015;71(45):8487-8510

82 (a) Butler DE, Deering CF, Millar A, et al. Improved process for (trans)-6-(2-(substituted-pyrrol-1-yl)alkyl)pyran-2-one inhibitors of cholesterol synthesis. EP Pat. 19890903348, Oct. 2, 1991. (b) Brower PL, Butler DE, Deering CF, et al. The synthesis of (4Rcis)-1,1-dimethylethyl 6-cyanomethyl-2,2-dimethyl-1,3-dioxane-4-acetate, a key intermediate for the preparation of CI-981, a highly potent, tissue selective inhibitor of HMG-CoA reductase. Tetrahedron Lett 1992;33(17):2279-2282. (c) Baumann KL, Butler DE, Deering CF, et al. The convergent synthesis of CI-981, an optically active, highly potent, tissue selective inhibitor of HMG-CoA reductase. Tetrahedron Lett 1992;33(17):2283-2284. (d) Shin H, Choi BS, Lee KK, et al. Efficient activation of zinc: application of the Blaise reaction to an expedient synthesis of a statin intermediate. Synthesis 2004;2004(16):2629-2632. (e) Sun R, Zhang FQ Du TJ, et al. Method for preparing (4R-cis)-6substituted-2,2-dimethyl-1,3-dioxane-4-tert-butyl acetate. CN Pat. 102180862, Sept. 14, 2011 (Chem Abstr 2011;155:457681)

83 (a) Chen FE, Yao J, Xiong FJ, et al. Trivalent cobalt Salen catalyst, synthesis method as well as application of trivalent cobalt Salen catalyst to resolution of terminal epoxides. CN Pat. 104801343, Jul. 29, 2015 (Chem Abstr 2015;163:289074). (b) Xiong F, Wang H, Yan L, et al. Diastereoselective synthesis of pitavastatin calcium via bismuth-catalyzed two-component hemiacetal/oxa-Michael addition reaction. Org Biomol Chem 2015;13(38):9813-9819. (c) Chen XF, Xiong FJ, Zheng C, et al. Synthetic studies on statins. Part 3: A facile synthesis of rosuvastatin calcium through catalytic enantioselective allylation strategy. Tetrahedron 2014;70 (35):5794-5799. (d) Chen WQ Xiong FJ, Liu Q et al. Substrate stereocontrol in bromine-induced intermolecular cyclization: asymmetric synthesis of pitavastatin calcium. Tetrahedron 2015;71(29):4730-4737. (e) Xiong F, Wang H, Yan L, et al. Stereocontrolled synthesis of rosuvastatin calcium via iodine chlorideinduced intramolecular cyclization. Org Biomol Chem 2016;14 (4):1363-1369. (f) Wu Y, Liu M, Huang HQ et al. Asymmetric synthesis of atorvastatin calcium through intramolecular oxidative oxygen-nucleophilic bromocyclization. Eur J Org Chem 2017;2017(25):3681-3688. (g) Chen FE, Xiong FJ, Wu Y, et al. Preparation method of 2-((4R,6S)-6-bromomethyl-2,2-dimethyl1,3-dioxane-4-yl)acetate. WO Pat. 2016074324A1, May. 19, 2016. Chem Abstr 2016;164:602165. (h) Chen FE, Xiong FJ, Wu Y, et al. Preparation method of 2-((4R,6S)-6-bromoethyl-2,2-dimethyl1,3-dioxyhexacyclo-4-yl)acetate. CN Pat. 104356109A, Feb. 18, 2015. Chem Abstr 2015;162:353216. (i) Chen FE, Xiong FJ, Li J, et al. Method for preparing rosuvastatin sodium. US Pat. 9850213B2, Dec. 16, 2017 (Chem Abstr 2014;160:341276)

84 (a) Chen X, Xiong F, Chen W, He Q Chen F. Asymmetric synthesis of the HMG-CoA reductase inhibitor atorvastatin calcium: an organocatalytic anhydride desymmetrization and cyanide-free side chain elongation approach. J Org Chem 2014;79(6):27232728. (b) Chen FE, Chen XF. Method for synthesizing (3R,5R)-3,5dihydroxy-6-cyanohexanoate. CN Pat. 103145584A, Jun. 12, 2013. Chem Abstr 2013;159:133729

85 (a) Johnson DV, Pöchlauer P, Griengl H. Process for selective reduction. US Pat. 6355822B1, Mar. 12, 2002 (Chem Abstr 2002; 136:232059). (b) Yatagai M, Ohnuki T. Asymmetric reduction of functionalized ketones with a sodium borohydride-(L)-tartaric acid system. J Chem Soc, Perkin Trans 1 1990; (6):1826-1828

86 (a) Huang G, Liu M, Xiong F, et al. Chiral syn-1,3-diol derivatives via a one-pot diastereoselective carboxylation/bromocyclization of homoallylic alcohols. iScience 2018;9:513-520. (b) Chen FR, Huang 
e54 Recent Advances of Pharmaceutical Process Chemistry and Its Innovation in China Tang et al.

GX, Wu Y, et al. Preparation method for (4S,6R)-4-bromomethyl-6substituted methyl-2-oxo-1,3-dioxane. CN Pat. 106588865A, Apr. 26, 2017. Chem Abstr 2017;166:515777. (c) Chen FE, Huang ZD, Meng G, et al. Preparation method for (R)-3-hydroxyl-5-hexenoate. US Pat. 20180340196A1, Nov. 29, 2018 (Chem Abstr 2017;167: 378668)
87 (a) Chen FE, Huang ZD, Peng HH, et al. Method for preparing (R)-3hydroxy-5-hexenoic acid ester. CN Pat. 107119081A, Sept. 1, 2017. Chem Abstr 2017;167:378668. (b) Chen FE, Huang ZD, Meng G, et al. Engineered bacterial strain and application of same to preparation of (R)-3-hydroxy-5-hexenoate. CN Pat. 108359626A, Aug. 3, 2018. Chem Abstr 2018;169:261711 